\title{
Temporal and spatial variability of auroral forms in the 10-14 MLT sector: Relationship to plasma convection and solar wind-magnetosphere coupling
}

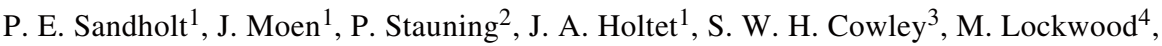 \\ U. P. Løvhaug 5 , T. Hansen ${ }^{6}$, and A. Egeland ${ }^{1}$ \\ ${ }^{1}$ Department of Physics, University of Oslo, Oslo, Norway \\ ${ }^{2}$ Danish Meteorological Institute, Copenhagen, Denmark \\ ${ }^{3}$ Department of Physics and Astronomy, University of Leicester, Leicester, U.K. \\ ${ }^{4}$ Rutherford-Appleton Laboratory, Chilton, Didcot, U.K. \\ ${ }^{5}$ EISCAT Scientific Association, Ramfjordmoen, Norway \\ ${ }^{6}$ Auroral Observatory, University of Troms $\phi$, Troms $\phi$, Norway
}

(Received November 8, 1996; Revised January 29, 1998; Accepted May 1, 1998)

\begin{abstract}
Ground-based observations of dayside auroral forms and magnetic perturbations in the arctic sectors of Svalbard and Greenland, in combination with the high-resolution measurements of ionospheric ion drift and temperature by the EISCAT radar, are used to study temporal/spatial structures of cusp-type auroral forms in relation to convection. Large-scale patterns of equivalent convection in the dayside polar ionosphere are derived from the magnetic observations in Greenland and Svalbard. This information is used to estimate the ionospheric convection pattern in the vicinity of the cusp/cleft aurora. The reported observations, covering the period 0700-1130 UT, on January 11,1993 , are separated into four intervals according to the observed characteristics of the aurora and ionospheric convection. The morphology and intensity of the aurora are very different in quiet and disturbed intervals. A latitudinally narrow zone of intense and dynamical $630.0 \mathrm{~nm}$ emission equatorward of $75^{\circ} \mathrm{MLAT}$, was observed during periods of enhanced antisunward convection in the cusp region. This (type 1 cusp aurora) is considered to be the signature of plasma entry via magnetopause reconnection at low magnetopause latitudes, i.e. the low-latitude boundary layer (LLBL). Another zone of weak $630.0 \mathrm{~nm}$ emission (type 2 cusp aurora) was observed to extend up to high latitudes $\left(\sim 79^{\circ} \mathrm{MLAT}\right)$ during relatively quiet magnetic conditions, when indications of reverse (sunward) convection was observed in the dayside polar cap. This is postulated to be a signature of merging between a northward directed IMF $\left(B_{Z}>0\right)$ and the geomagnetic field poleward of the cusp. The coexistence of type 1 and 2 auroras was observed under intermediate circumstances. The optical observations from Svalbard and Greenland were also used to determine the temporal and spatial evolution of type 1 auroral forms, i.e. poleward-moving auroral events occurring in the vicinity of a rotational convection reversal in the early post-noon sector. Each event appeared as a local brightening at the equatorward boundary of the pre-existing type 1 cusp aurora, followed by poleward and eastward expansions of luminosity. The auroral events were associated with poleward-moving surges of enhanced ionospheric convection and $F$-layer ion temperature as observed by the EISCAT radar in Troms $\varnothing$. The EISCAT ion flow data in combination with the auroral observations show strong evidence for plasma flow across the open/closed field line boundary.
\end{abstract}

\section{Introduction}

Particle precipitation from different magnetospheric boundary layer plasma sources, such as the central plasma sheet (CPS), the boundary plasma sheet (BPS), low-latitudinal boundary layer (LLBL), the cusp and the plasma mantle gives rise to dayside high latitude auroral emissions. The relationships between particle precipitation and auroral emissions in this region can be studied by combining observations from the ground and satellites in polar orbit (cf. Sandholt and Newell, 1992; Sandholt et al., 1993a, b; Øieroset et al., 1997a, b). The dayside precipitation pattern and the associated auroral forms are strongly variable and dynamic, due to the sensitivity of magnetospheric boundary layer plasmas to the variable conditions in the magnetosheath/

Copy right (C) The Society of Geomagnetism and Earth, Planetary and Space Sciences (SGEPSS); The Seismological Society of Japan; The Volcanological Society of Japan; The Geodetic Society of Japan; The Japanese Society for Planetary Sciences. solar wind. Responses of the auroral forms in the cusp region to changing orientation of the interplanetary magnetic field (IMF) and solar wind dynamic pressure have been documented in recent studies (e.g. Sandholt et al., 1993a, 1994, 1996a, b).

The high-latitude ionospheric convection pattern in the midday sector also depends strongly on the IMF-orientation and the associated electric field coupling between the solar wind and the ionosphere (e.g. Heppner and Maynard, 1987; Rich and Hairston, 1994; Stauning et al., 1994). The relationships between the various precipitation components/ auroral forms in the cusp/cleft region and plasma convection is less well known at present. In this study we concentrate on the variability of auroral emissions in the midday sector ( 1000-1400 MLT; 70-77 ${ }^{\circ}$ MLAT) and its relation to plasma convection for different levels of magnetospheric activity, based on observations made during a four hour interval on January 11, 1993. Available ionospheric flow 
data from the EISCAT radar is used to obtain a more accurate determination of the relationship between auroral activities and convection in the cusp region.

The statistical pattern of particle precipitation in the dayside magnetosphere has been determind by Newell and Meng (1988, 1992) and Lundin et al. (1991).

Since the detailed identification of the magnetospheric source plasma from optical observations of dayside auroral emissions can be problematic in individual cases, the band of auroral emission at cusp/cleft latitudes within 09-15 MLT is often referred so as the cusp/cleft aurora (Sandholt et al., 1993a, b, 1994).

Two different auroral forms, located at different latitudes in the cusp/cleft region, called type 1 (south) and type 2 (north), have been identified from ground observations (Sandholt et al., 1996a, b). Transitions from one form to the other often occur in association with IMF rotations involving $B_{Z}$ polarity changes. The two auroral forms may thus correspond to different plasma entry sites at the magnetopause, presumably at low and high magnetopause latitudes, respectively. In this study it is shown that the type 1 (south) and type 2 (north) auroral forms are associated with different states of polar cap convection. Furthermore, both forms are observed to be simultaneously present (hybrid cusp) during intervals characterised by an intermediate state of polar cap convection.

It is noted that only indirect information on the IMF conditions is available for the case discussed in this paper.

In order to be able to distinguish between spatial and temporal variability of auroral emissions and their relationships with plasma convection in the cusp/cleft region, observations from stations covering wide ranges in latitude and longitude are combined, i.e. the North Norway-Svalbard chain and the Greenland east- and westcoast chains. The parameters observed are optical aurora from Svalbard and Greenland, high-resolution $F$-layer ion drift and temperature obtained from the EISCAT radar, and ground magnetic field deflections from these three meridian chains. The magnetometer data allow us to infer the spatial-temporal structure of the large-scale dayside convection pattern. The high-resolution line-of-sight measurements by the EISCAT UHF and VHF antennas are used to monitor the temporalspatial variability of convection at the polar cap boundary in the Svalbard sector (Lockwood et al., 1993).

If the open/closed field line boundary (magnetic separatrix) can be identified from the optical observations, a search for ion flow across the separatrix, which is a characteristic signature of the magnetic reconnection process (Vasyliunas,

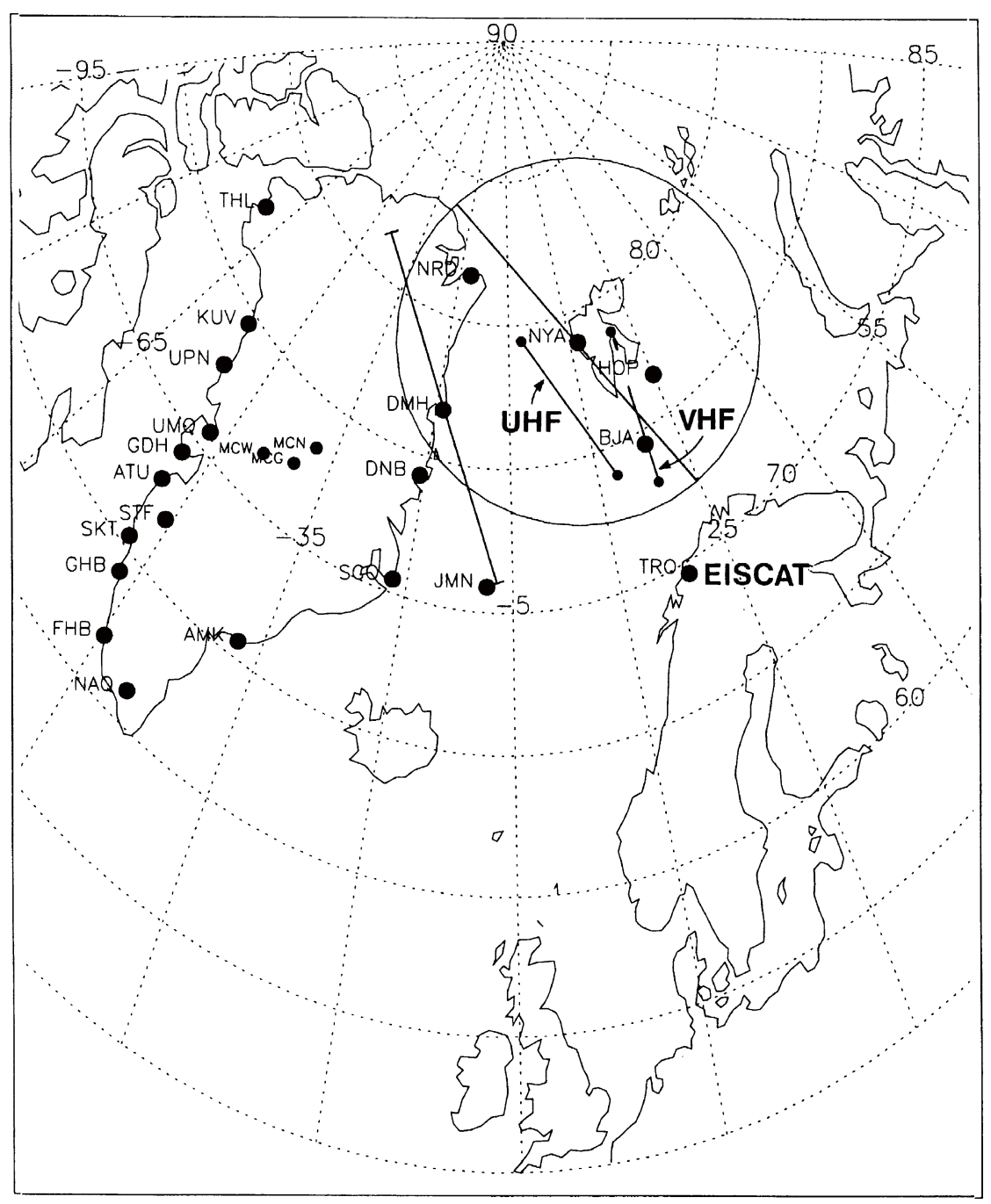

Fig. 1. Map of station locations and fields-of-view of optical and radar observations in the Greenland and Svalbard sectors of the Arctic. 
1984), can be made. Of particular interest is the question of variability of the magnetopause reconnection rate and its possible relationship with magnetopause flux transfer event signatures (Russell and Elphic, 1979) and optical auroral events observed at the dayside polar cap boundary during intervals of southward-directed interplanetary magnetic field (IMF $B_{Z}<0$ ) (Sandholt et al., 1989a, 1993a, b). Such auroral events are observed to be associated with shortlived bursts of enhanced convection (e.g. Lockwood et al., 1990a, b). So far it has not been demonstrated that the ion drift crosses the magnetic separatrix in such cases. The major difficulties have been related to the separatrix identification and the spatial/temporal resolution of the ion drift data. Furthermore, it has recently been shown that solar wind dynamic pressure pulses may give rise to similar auroral events (Sandholt et al., 1994). Thus, a more careful investigation of the possible relationship between magnetopause reconnection and auroral events in the cusp ionosphere is necessary. One way of obtaining new information on this problem is by studying the time-history of the ion drift pattern in the dayside throat region during periods of auroral event occurrence.

On January 11, 1993 poleward-moving auroral events and related ionospheric ion temperature enhancements were observed in the vicinity of a rotational convection reversal at the polar cap boundary in the early post-noon sector during an interval of enhanced large-scale dayside convection.

The observation are interpreted in terms of a model describing the relationships between particle precipitation and convection during intervals of active magnetopause reconnection.

\section{Observations}

Figure 1 shows the geographical location of stations in north Norway, Svalbard and Greenland which are used in this study. Fields-of-view of the photometer systems located in Ny Ålesund (NYA) and Danmarkshavn (DMH) as well as the approximate field-of-view of the all-sky TV camera in Ny Ålesund are marked in the figure. The two sites are separated by $\sim 2 \mathrm{~h}$ in local time. Magnetic noon in $\mathrm{Ny}$ Ålesund and Danmarkshavn occur at 0900 and 1100 UT, respectively. Also shown are the EISCAT UHF and VHF radar beams for the SP-NO-CONV experiment. The altitude of the UHF radar beams varies from $197 \mathrm{~km}$ for gate 1 to 595 $\mathrm{km}$ for gate 25 .

The observations reported here cover the interval from 0700 to 1130 UT on January 11, 1993. This period is divided into the following four sub-intervals, according to certain characteristics of the physical parameters considered, i.e., ground magnetic disturbance, EISCAT ion drift and auroral structure and activity: I: 0700-0815 UT, II: 0815-0910 UT, III: 0910-1110 UT, IV: 1110-1130 UT.

\subsection{Optical aurora}

The aurora recorded from Ny Ålesund, Svalbard during interval I, corresponding to the local time period $\sim 10-11$ MLT, is characterized by a steady, weak auroral emission at $630.0 \mathrm{~nm}$ spanning a large range of zenith angles, i.e. from $\sim 30$ degree south to $\sim 50$ degree north of zenith (cf. Fig. 2(a)). The maximum line-of-sight intensity is $\sim 1 \mathrm{kR}$. Assuming an emission altitude of $300 \mathrm{~km}$ this corresponds to the latitude range from $\sim 74.5$ to $78.5^{\circ}$ MLAT. The $630.0 \mathrm{~nm}$ aurora is only weakly structured.

Figure 2(b) shows that a rather strong $(\sim 2-3 \mathrm{kR})$, more narrow $630.0 \mathrm{~nm}$ aurora appeared at $\sim 0820$ UT $(\sim 1120$ MLT), 25 degree south of zenith. Thus, interval II (08150910 UT) is characterized by two auroral forms separated in latitude, i.e. a wide zone of emission north of zenith (type 2) and a more narrow intense form at its equatorward boundary (type 1). The latter aurora, also containing $\sim 1 \mathrm{kR}$ green line emission, becomes increasingly dominant towards the end of this interval. It has a sharp equatorward boundary and consists of a sequence of brightenings, which are separated by $\sim 5 \mathrm{~min}$. They are marked in the figure.

Figure 2(c) shows Ny Ålesund photometer scans at 630.0 $\mathrm{nm}$ for the interval 0900-1130 UT ( 1200-1430 MLT). Interval III (0910-1110 UT) is characterized by a persistent aurora of variable intensity (2-3 kR) which is migrating equatorward from $\sim 18$ to $\sim 52$ degree south of zenith and a sequence of transient events. Interval IV (1110-1130 UT) shows a persistent aurora of variable intensity at $\sim 50$ degree south of zenith. Transient forms separating from the background aurora on its poleward side are not observed in this interval.

Figure 2(d) shows meridian photometer scans from Danmarkshavn (DMH), Greenland for the same interval 0900-1130 UT as Fig. 2(c), but at this site 0900-1130 UT corresponds to $\sim 1000-1230$ MLT. A sequence of transient auroral forms at the poleward boundary of a persistent aurora is observed during interval III (0910-1100 UT). 14 events in $100 \mathrm{~min}(0920-1100 \mathrm{UT})$ gives a mean repetition period of $7.1 \mathrm{~min}$. A pronounced intensification of the southernmost aurora occurred at $\sim 948$ UT. Interval IV is characterized by a weak persistent aurora centred at 50 degree south of zenith and no transient forms at its poleward boundary, i.e. a very quiet auroral situation.

Two-dimensional images of the above mentioned auroral events, i.e. eastward and northward moving auroral forms, are given in Figs. 3(a) and 3(b). Figure 3(a) shows a picture sequence of the $630.0 \mathrm{~nm}$ emission for the interval 10511056 UT. The auroral emission is projected to an Earthcentred sphere at $300 \mathrm{~km}$ altitude, displayed on the background of a geographic reference frame. The aurora is intensified at these times (Figs. 2(c) and 2(d)) and an eastward-moving form is easily identified in the area between the Greenland east-coast and Svalbard. This eastwardmoving event entered the camera field of view at $1052 \mathrm{UT}$, slightly equatorward of Danmarkshavn (DMH) (cf. also the event marked on the Danmarkshavn photometer traces in Fig. 2(d)). At 1055 UT the leading front of the event reached approximately midway between Danmarkshavn and $\mathrm{Ny}$ Ålesund (stations are marked by white squares in Fig. 3), before it faded away.

At 1055 UT a new auroral intensification occurred further south between Greenland and Svalbard, i.e. at latitudes between Scoresbysund (SCO) and Daneborg (DNB) (cf. Fig. 1). Figure 3(b) shows that this event expanded poleward, separating from the persistent aurora. This phase of the evolution of the event is sketched on the Ny Ålesund photometer traces at 1058 to 1102 UT in Fig. 2(c). 


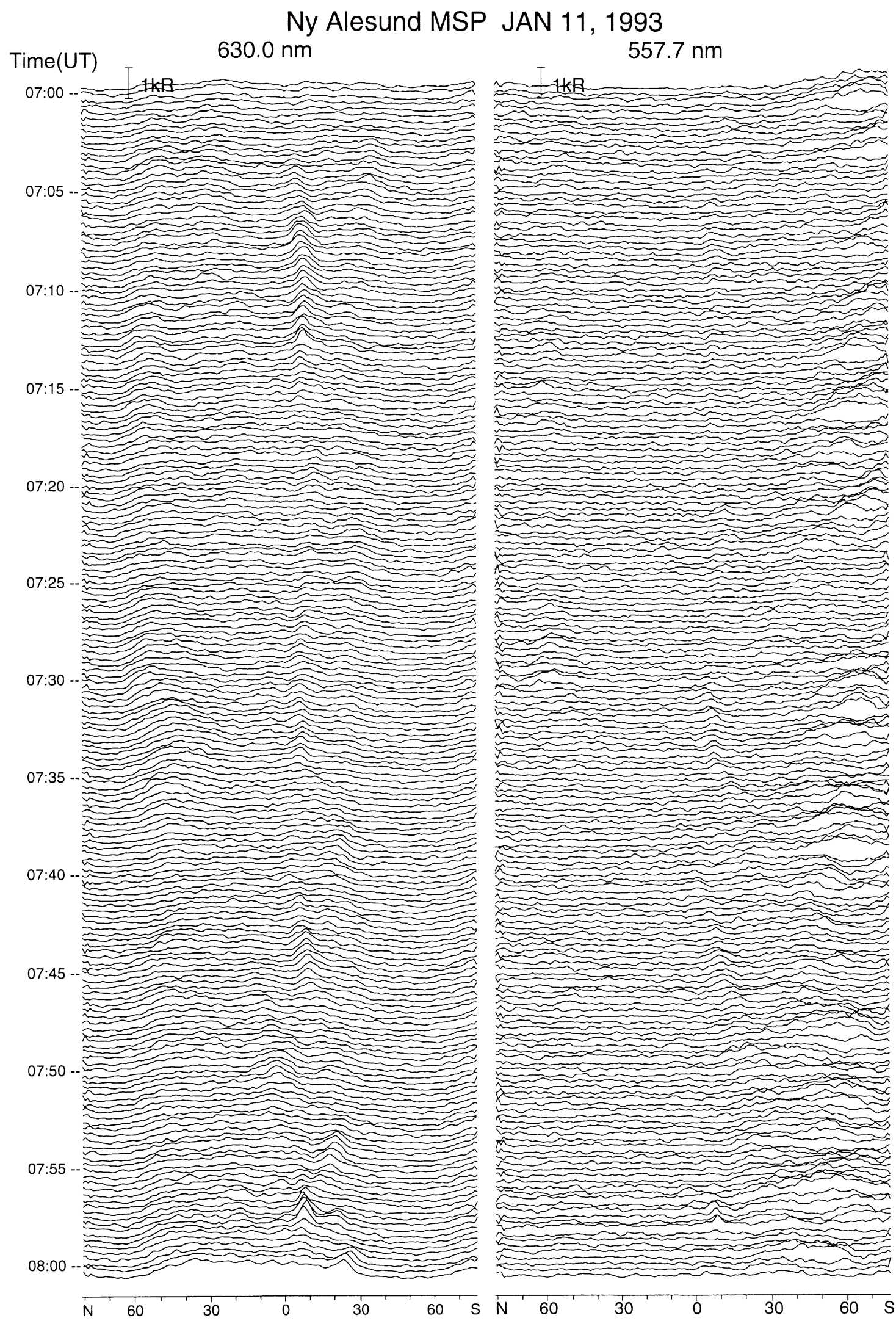

(a)

Fig. 2. (a)-(c) Meridian scanning photometer (MSP) traces (intensity versus zenith angle) from Ny Ålesund (NY $\AA$ ) for the time intervals (a) $0700-$ 0800 UT, (b) 0800-0900 UT, (c) 0900-1130 UT. The oxygen lines at 630.0 and $557.7 \mathrm{~nm}$ are plotted in the left and right panels, respectively. Transient auroral events are marked by thick lines. Different cusp auroral forms are marked in Fig. 2(b). (d) MSP plots from Danmarkshavn (DMH) for the 0900-1130 UT interval. Arrows at $\sim 0948$ and 1100 UT mark the beginning and end of period with strong cusp aurora observed from Danmarkshavn. Transient auroral forms are marked by thick lines. 


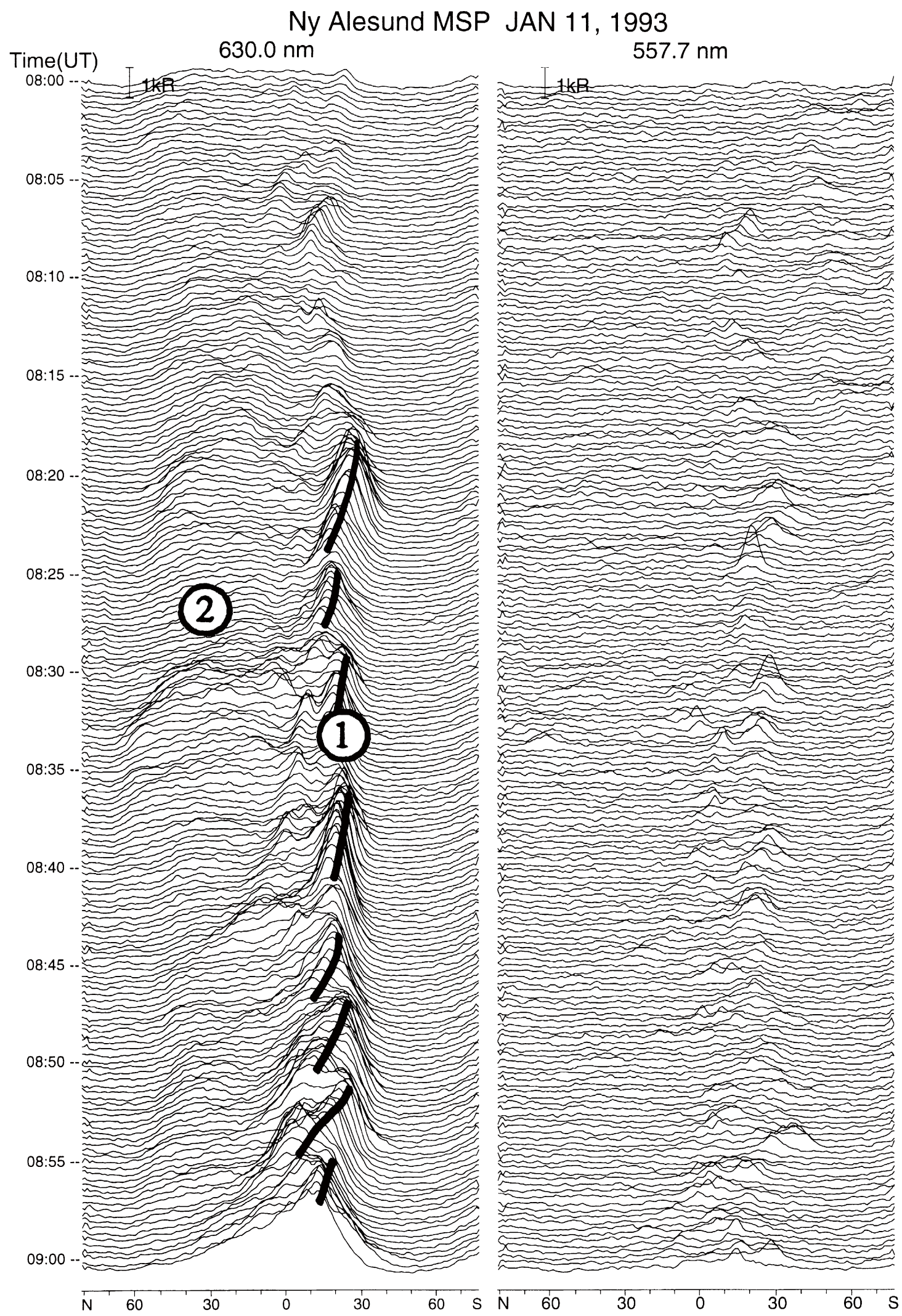

(b)

Fig. 2. (continued)

\subsection{Ground magnetic perturbations}

Figure 4 shows Ny Ålesund $Z, D$ and $H$-component magnetograms for the interval of interest in this study. Intervals I and II are rather quiet. Magnetic deflections are less than $20 \mathrm{nT}$. Interval III is characterized by a significant negative $H$-component deflection, reaching a peak value of $\sim 100 \mathrm{nT}$ during the period $\sim 1040-1100$ UT. During interval IV the $H$-component disturbance in Ny Ålesund again ap- 
Ny Alesund MSP JAN 11, 1993
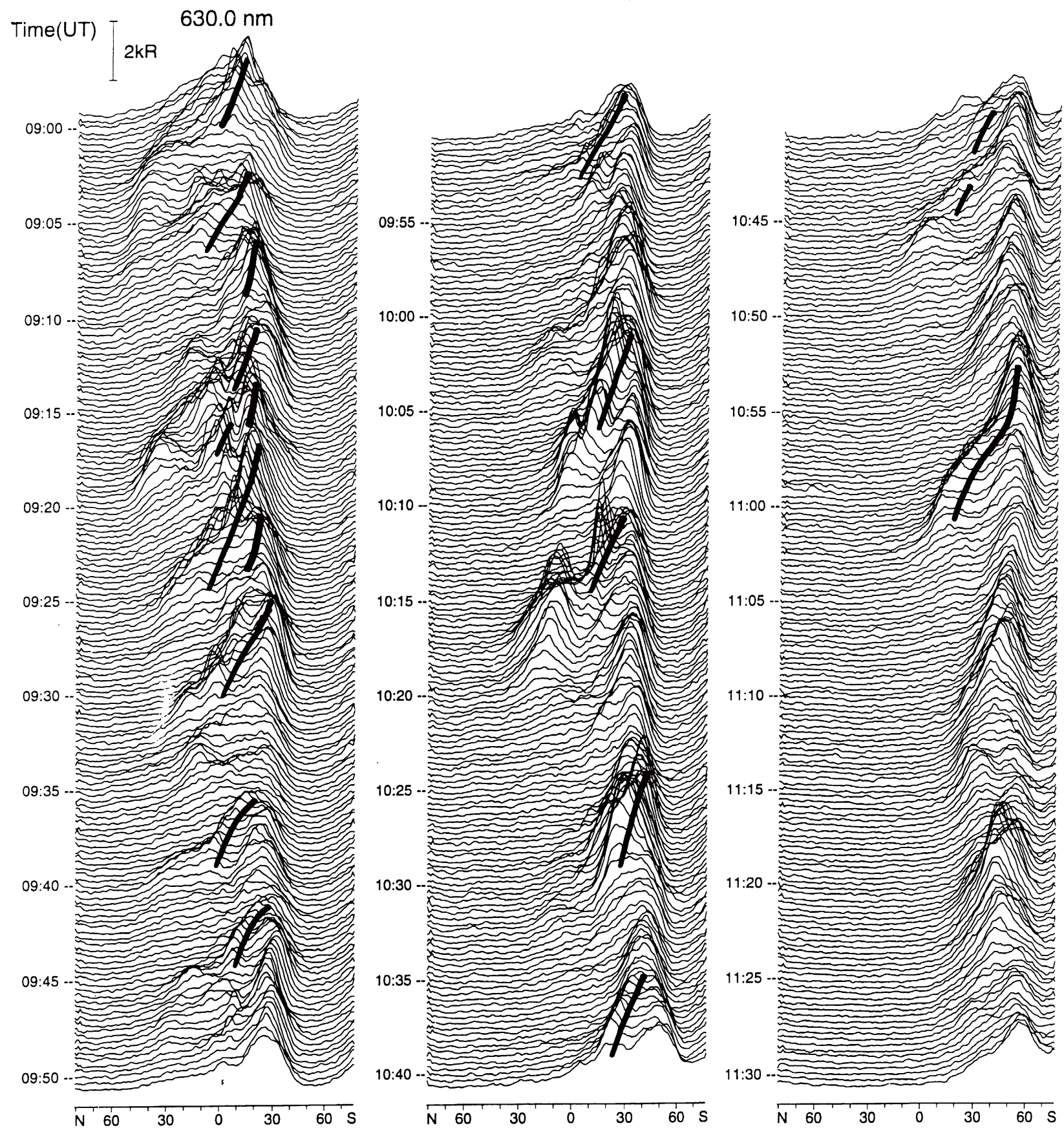

(c)

Fig. 2. (continued).

proached the quiet time level of intervals I and II.

Figure 5 shows stack-plots of $H$-component deflections from the Greenland west- and east-coast stations marked in Fig. 1. The 11 uppermost traces represents the west-coast (THL-NAQ), whereas the lower eight (NRD-AMK) represents the east-coast and icecap stations. Intervals I to IV are marked in the figure. As indicated in the Ny Alesund magnetograms a significant level of disturbance is limited to interval III, in particular the periods 0930-1000 and 10301100 UT. Maxima in $H$-component deflections occurred at
0950, 1035, and 1055 UT. The latter event is marked by a vertical dashed line in Fig. 5. We note that the 1055 UT deflection event was seen over wide ranges of latitudes and longitudes. The transient auroral event occurring at this time was observed slightly equatorward of Danmarkshavn (cf. Figs. 2(d) and 3(a)). The subsequent magnetic deflection enhancement ( 1055-1105 UT) was observed at somewhat lower latitudes (cf. magnetometer traces from stations FHB, NAQ, SCO, and AMK, in Fig. 5). The corresponding auroral event appeared as a brightening within the background 


\section{Danmarkshavn MSP JAN 11, 1993}
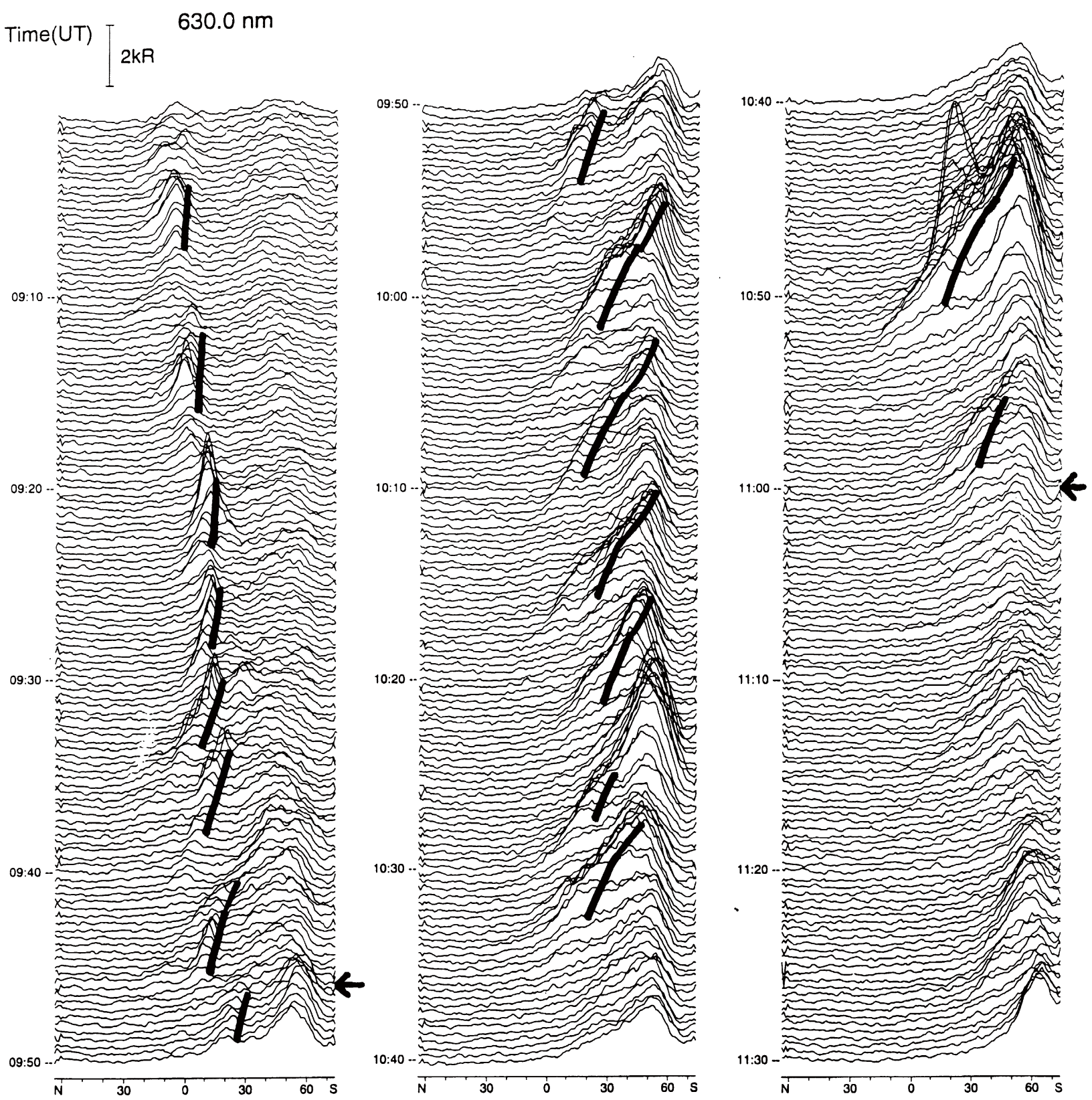

(d)

Fig. 2. (continued)

aurora between Greenland and Svalbard (cf. Fig. 3(b)), i.e. well equatorward of the previous auroral event. This event also expanded further eastward before fading.

\subsection{Plasma convection data in relation to the optical observations}

Figures 6(a)-(d) shows maps of equivalent convection in the $\sim 06-12$ MLT sector for the selected times 0700, 0800, 0830 and 0930 UT (intervals I, II and III, respectively). The location of auroral forms observed from Ny Ålesund and Danmarkshavn is also marked in the figure. The positions of Ny Ålesund (Figs. 6(a)-(d)) and Danmarkshavn (Fig. 6(d)) have been marked by solid dots. Horizontal magnetic perturbation vectors observed in the sectors of Greenland and
Svalbard have been rotated $90^{\circ}$ counter-clockwise in order to obtain the plotted equivalent convection vectors. (The vectors are aligned with and proportional to the plasma convection if magnetometers are responding primarily to Hall currents.) The heavy arrowed lines in Fig. 6 mark the pattern of equivalent convection, as derived from the magnetometer data. Note in Figs. 6(a) and 6(b) that convection is sunward at very high latitudes $\left(\geq 80^{\circ}\right)$.

The latitudinal extent of the weak $630.0 \mathrm{~nm}$ auroral emission (type 2) observed from Ny Ålesund, extending up to high latitudes $\left(\sim 79^{\circ}\right.$ MLAT), is marked by a bar in Figs. 6(a), 6(b) and 6(c). The single-hatched area in Figs. 6(c) and 6(d) marks the location the type 1 aurora. The cross-hatched 
(a)

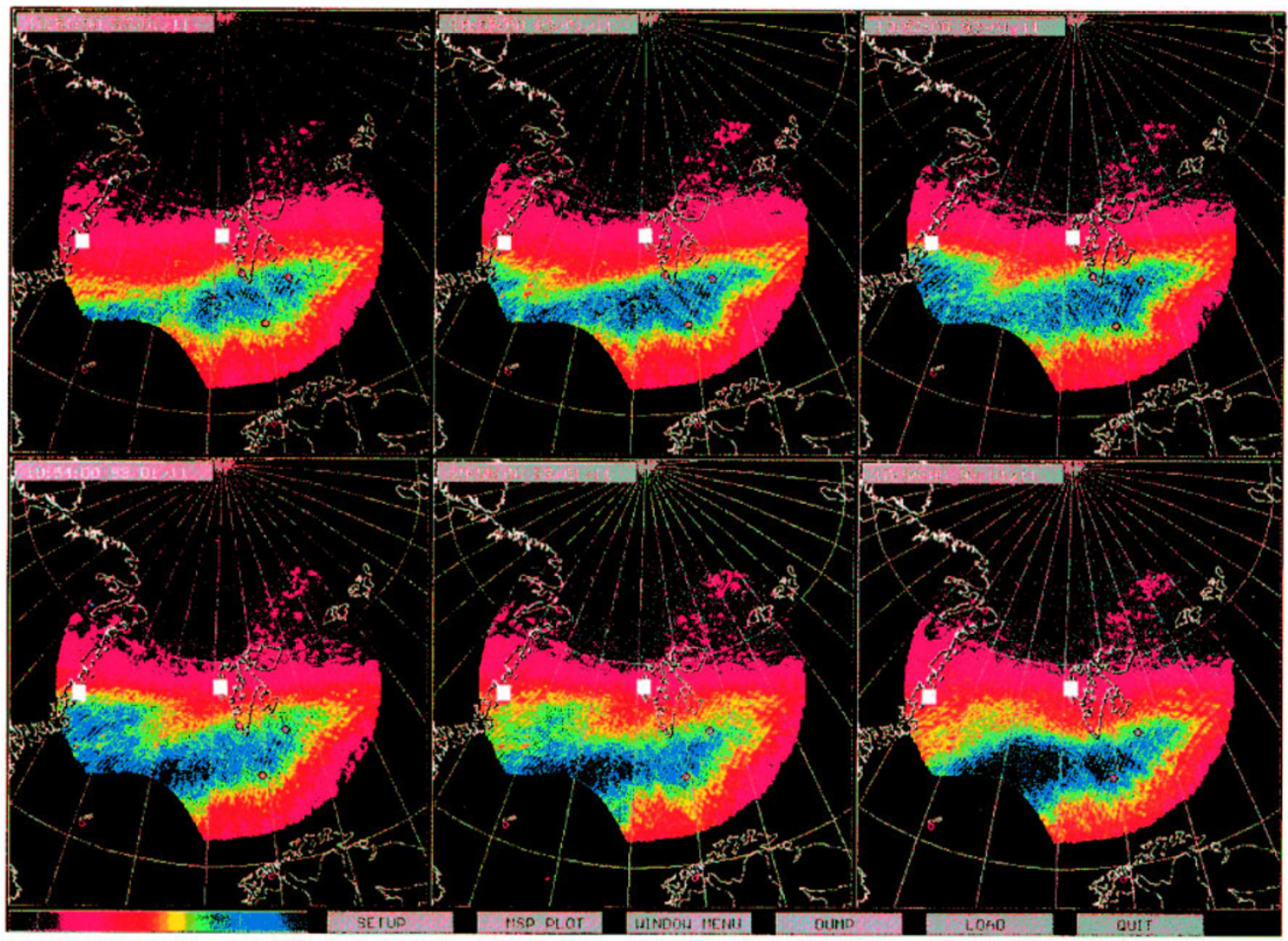

(b)

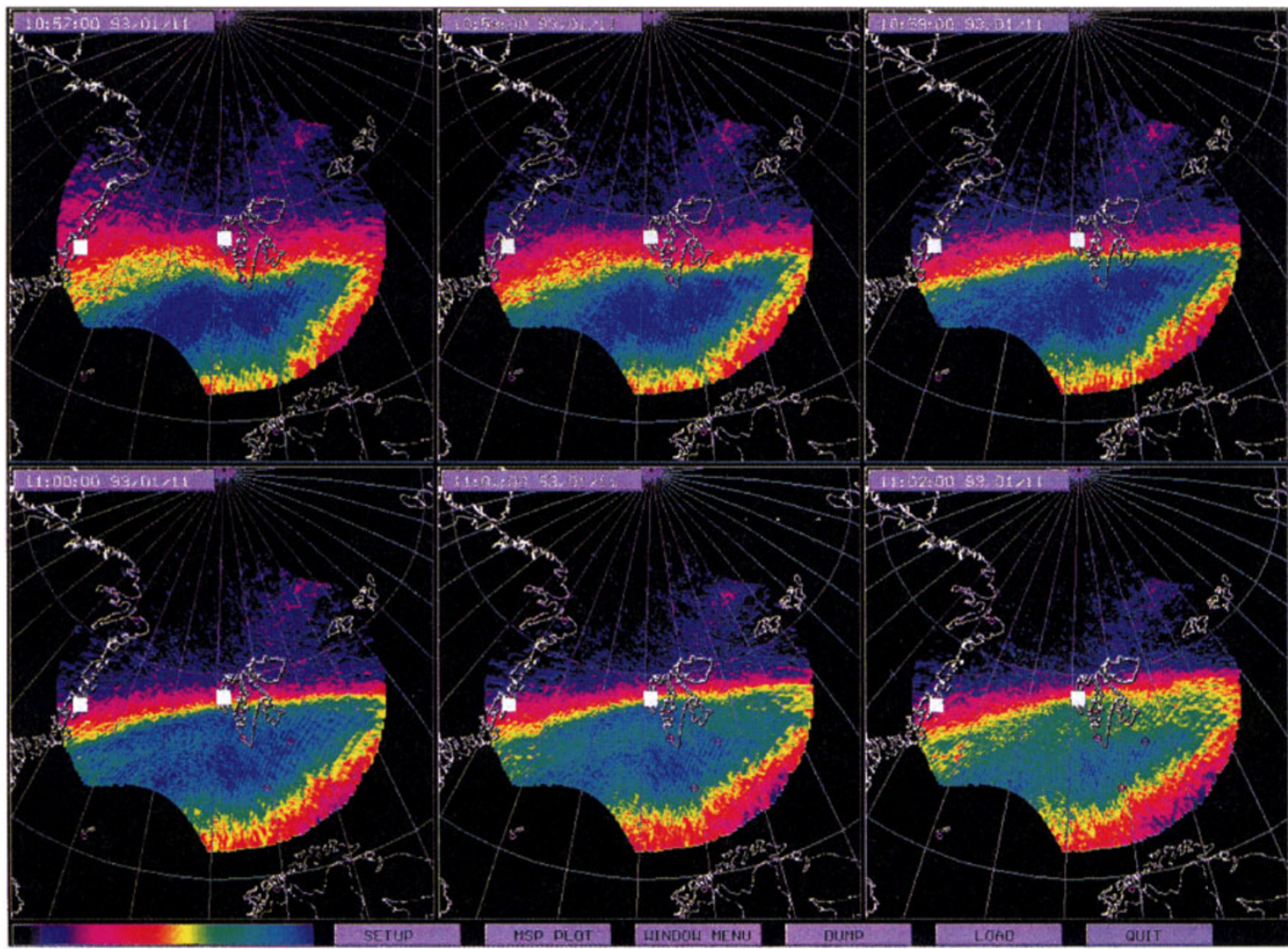

Fig. 3. (a), (b) Sequences of auroral all-sky-TV pictures $(630.0 \mathrm{~nm})$ for the intervals (a) $1051-1056 \mathrm{UT}$ and (b) 1057-1102 UT. The $630.0 \mathrm{~nm}$ emission projected to a spherical surface at $300 \mathrm{~km}$ altitude is shown on the background of a geographical reference frame. The optical sites at Danmarkshavn, Greenland and Ny Ålesund, Svalbard (the center of the figure) are marked by white squares. 


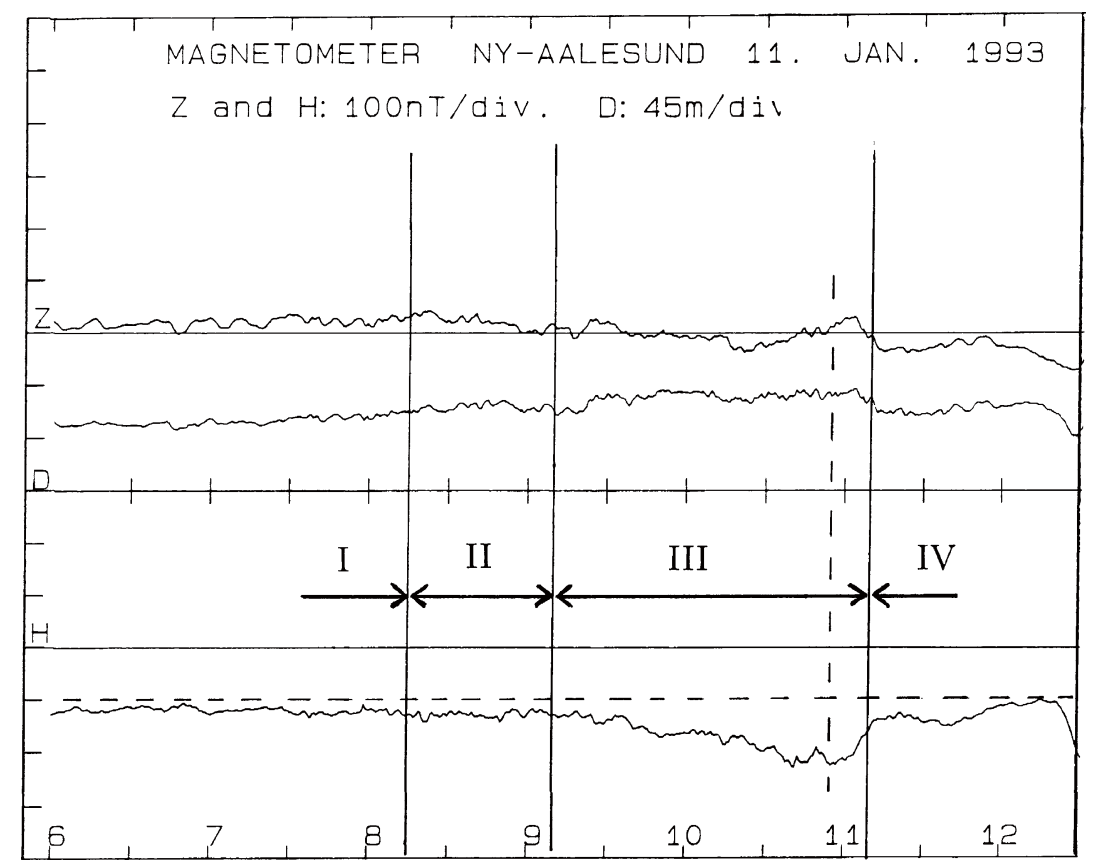

Fig. 4. Ny Ålesund $Z, D$ - and $H$-component magnetograms for the interval 0600-1230 UT. Intervals representing different levels of magnetic disturbance and corresponding ionospheric convection are marked by vertical lines. Onset time of the last auroral and convection event (1055 UT; cf. Fig. 8) is marked by dashed vertical line.

region in Fig. 6(d) represents a sequence of transient auroral forms disappearing poleward of the persistent background aurora. The optical sites at Ny Ålesund (NYA) and Danmarkshavn (DMH) are indicated by solid dots. Figure 6 illustrates the relationship between the different types of auroral forms and activities and the corresponding plasma convection patterns, which will be discussed further in Subsection 3.3 below.

Figure 7 shows ionospheric $F$-layer ion drift and temperature data at $5 \mathrm{~min}$ resolution obtained by the EISCAT UHF and VHF radar beams of the SP-NO-CONV experiment. The data from the UHF and the VHF antennas are displayed in the two upper and the two lower panels, respectively. The altitude of the scattering volumes is shown along the left side vertical axis. We will concentrate on the line-of-sight (l-o-s)-velocities.

The coverage of the two radar antennas in relation to the field-of-view of the optical instruments is indicated in Fig. 1. Positive and negative values in the velocity panel in Fig. 7 correspond to away and toward velocities, respectively.

In interval I velocities are generally small (green or yellow colour) at all 25 range gates, although the VHF data indicate some high away velocities (red colour) in the gates located farthest north. Ion temperatures are low (dark blue).

During interval II (0815-0910 UT) the UHF data shows somewhat higher away velocities northward of gate $\sim 8$. In interval III (0910-1110 UT) velocities are generally higher than in the previous periods. We also notice that the highvelocity regime extends to lower latitudes.

The prevailing convection pattern during the interval 0930-1000 UT (interval III) and its relation to the optical auroral observations are indicated in Fig. 8. The location of the type $1 \mathrm{cusp} / \mathrm{cleft}$ aurora as well as the observed sequence of shortlived $(\sim 10 \mathrm{~min})$, poleward-moving auroral forms are marked respectively by the single- and cross-hatched zones in the figure. The indicated convection pattern is based on the combination of line-of-sight velocities from the EISCAT UHF and VHF radars in the 0930-1000 UT interval as well as equivalent convection obtained from the ground magnetic deflections (cf. Figs. 4 and 5). Fields-of-view of the scanning photometers operated in Danmarkshavn, (DMH), Greenland and Ny Ålesund (NY ̊), Svalbard as well as of the EISCAT antennas are marked by straight lines.

The interval from 1030 to 1110 UT shows a high-velocity regime extending to the lowest gates of the UHF radar, as documented in Fig. 7. The ion temperature shows some features in this interval which are correlated with the ion drift events (cf. Fig. 7, panels 1 and 2). F-layer temperatures obtained by the UHF radar are displayed in more detail in Fig. 9. We notice two events of poleward-moving hightemperature regimes during the intervals 1035-1042 and 1050-1105 UT. The latter is marked by a dashed vertical line in the figure. These events are manifested as negative $H$ component magnetic deflections within a wide range of latitudes and longitudes (cf. Figs. 4 and 5). Distinct auroral events are observed in association with the latter interval (cf. Figs. 2(c), 2(d) and 3(b)).

Figure 10 shows an equivalent convection pattern and its relation to auroral forms in the $12-15$ MLT region for 1055 UT, i.e. the auroral event presented in Fig. 3, derived from the combined observations presented above. The shortlived auroral form (cross-hatched area) appeared near the equatorward boundary of the pre-existing type 1 aurora (hatched area).

Figure 11 shows ion drift vectors within the EISCAT latitudinal range obtained by combining line-of-sight velocities from the two radars for the 1056-1106 UT interval. Ion temperatures are shown superimposed (colour-coded 


\section{GREENLAND}

MAGNETOMETER CHAIN H JAN 111993

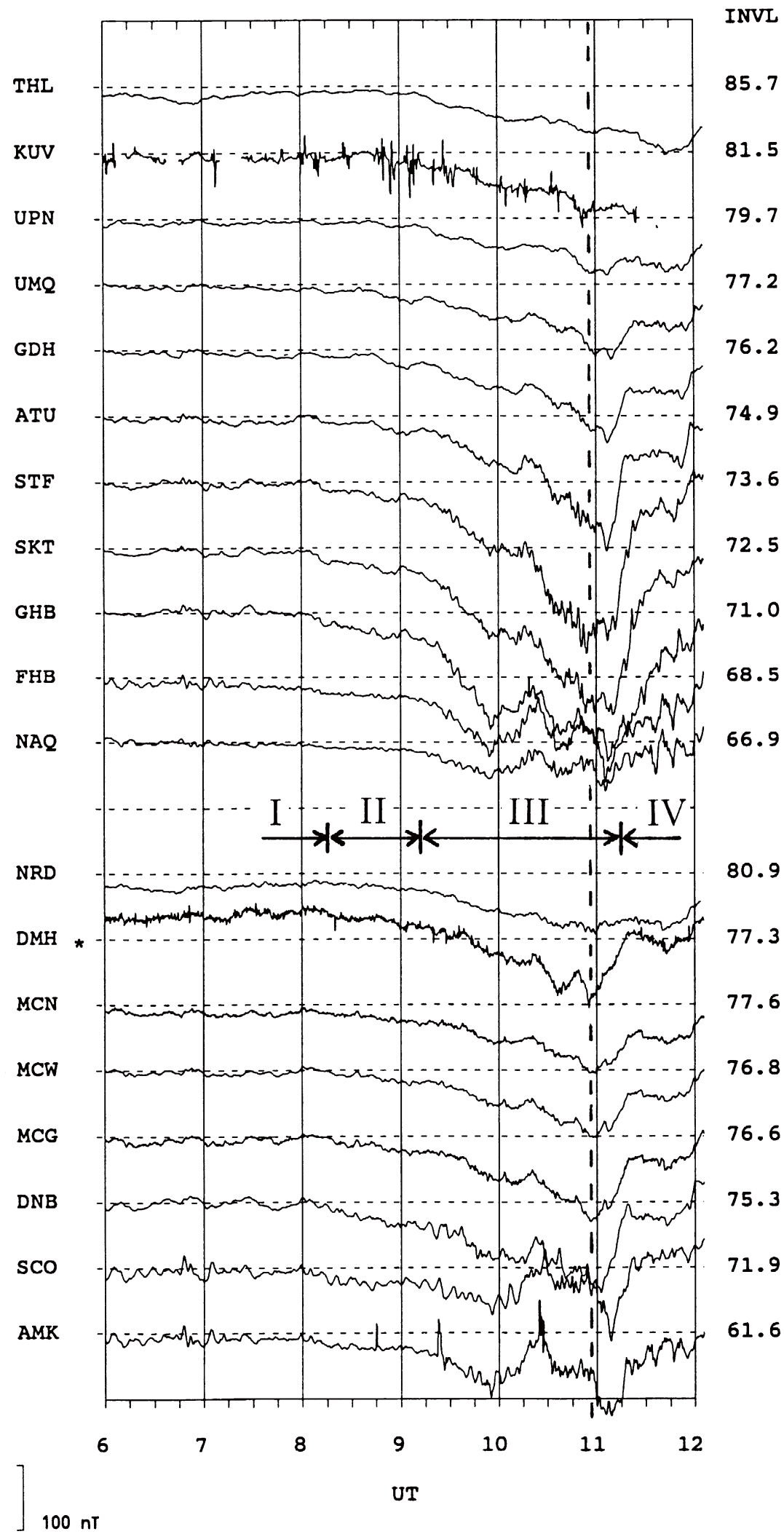

Fig. 5. Greenland chain $H$-component magnetograms for the interval 0600-1200 UT. The first 11 traces (THL-NAQ) represent the westcoast chain, while the lower five (NRD-AMK) are records from the eastcoast chain. Four intervals of different convection-intensity are marked by vertical lines. The onset of the last auroral event (1055 UT) is marked by dashed vertical line. 
scale). The procedure applied for deriving the vectors assumes a homogenous ionosphere within a volume which includes the two radar beams. The time interval of the auroral event as well as its latitudinal location (vertical bar) as observed by the scanning photometer in Ny Ålesund is indicated in the figure. A clear rotational convection reversal at $\sim 74^{\circ}$ INVL with a region of strong eastward convection further north, between 74 and $76^{\circ}$ INVL, is observed. The channel of eastward convection and elevated ion temperatures is collocated with the auroral event in its fading phase, after 1100 UT.

The early phase of the auroral event is marked in Fig. 10. After the interval shown in Fig. 11 there was a marked decrease of ion drift velocities at $\sim 1110$ UT. The interval from 1110 to 1130 UT is characterized by low line-of-sight speeds. Corresponding decreases of the auroral intensity and activity and the ground magnetic deflections are observed (period IV).

\subsection{Summary of observations}

Interval I (0700-0815 UT) was characterized by very quiet auroral and magnetic conditions and sunward ionospheric convection at high latitudes, showing either reverse (sunward) polar cap convection or a highly contracted polar cap. Given the sunward flow poleward of the poleward edge of the aurora we can infer reverse (IMF $B_{Z}>0$ ) polar cap convection at this time. The type 2 auroral luminosity at $630.0 \mathrm{~nm}$ was weak $(\sim 1 \mathrm{kR})$ and covered a wide range of zenith angles in the north-south direction and no discrete forms were observed within the field of view of the scanning photometer in Ny Allesund. The poleward boundary of this luminosity was located at $\sim 79^{\circ}$ MLAT, assuming an emission altitude of $300 \mathrm{~km}$ (Figs. 6(a) and 6(b)).

Interval II (0815-0910 UT) shows the simultaneous existence of two different auroral forms, i.e. a rather narrow zone of intense $(2-3 \mathrm{kR})$ red line aurora (type 1) at the equatorward boundary of the wider zone of emission in the north (type 2). The lower-latitude aurora consists of a sequence of auroral brightenings which are marked in Fig. 2(b). The EISCAT UHF antenna and the ground magnetometers detected higher convection speeds at cusp/cleft latitudes than in interval I (Fig. 6(c)). The high-latitude convection was consistent with a lobe circulation cell with flow towards dusk at noon (IMF $\left.B_{Y}<0\right)$.

Interval III (0910-1110 UT) was the most active period, with enhanced convection velocities spanning wider ranges of latitudes and longitudes, associated magnetic deflections and a sequence of short-lived ( $<10 \mathrm{~min})$ eastward-moving auroral forms at the poleward boundary of the type $1 \mathrm{cusp} /$ cleft aurora (Fig. 6(d)). The auroral events were associated with distinct convection enhancements and corresponding ground magnetic deflections observed within a wide range of latitudes and longitudes on the dayside. The eastward flow across noon intensified and flows were consistent with IMF $B_{Z}<0$ and $B_{Y}<0$ conditions. The zone of weak 630.0 $\mathrm{nm}$ aurora at high latitudes (type 2 ) was absent in this period. The auroral events often appeared as an intensification of the pre-existing type $1 \mathrm{cusp} / \mathrm{cleft}$ luminosity (cf. the hatched areas in Fig. 10), which is followed by poleward and eastward expansions and subsequent fading away of the luminosity after 5-10 $\mathrm{min}$.
During interval IV (1110-1130 UT) quiet conditions were re-established, as manifested in slower ion drift (convection), lower auroral emission intensity and activity and smaller ground magnetic deflection. We notice in particular that the auroral event sequence ended at $\sim 1105$ UT (cf. Fig. 2(d)).

\section{Discussion}

The discussion here concentrates on the following topics: i) identification of different cusp auroral forms, based on their morphological and spectral characteristics and relationship with the ionospheric convection configuration, ii) identification of the open/closed boundary (magnetic field separatrix) from the optical observations, iii) the structure and dynamics of the ionospheric ion drift pattern in the vicinity of the open/closed boundary, and iv) EISCAT ion drift observations in relation to auroral events.

\subsection{Dayside auroras: Comment on the identification of magnetospheric plasma sources}

The main auroral emission observed in the $\sim 09-15$ MLT sector has in previous studies been termed the cusp/cleft aurora. This is because soft magnetosheath-like electron and ion precipitations are classified as "cleft" or "cusp" depending on the spectral characteristics, but as the two cause very similar $630.0 \mathrm{~nm}$-dominant emission, it can be very hard to distinguish the two in scanning photometer data. At least during negative IMF $B_{Z}$ condition it is difficult to distinguish between cusp and cleft auroral components in the 0915 MLT sector (Sandholt et al., 1994).

The main auroral distinction in the midday sector is between the cusp/cleft auroral bands (type 1 and 2 forms) and the diffuse aurora further south, the latter being the signature of magnetospheric particles precipitating at lower latitudes, the dayside extension of the plasma sheet (Sandholt et al., 1996a). It is easy to distinguish between these auroral forms (rayed bands versus diffuse glow).

A transition from a strongly red-dominated emission near noon (cusp-type) to a luminosity containing higher green line intensities in the post-noon sector (cleft-type) is often observed, in particular during negative IMF $B_{Y}$ conditions (Farrugia et al., 1995). This cleft-type aurora occurs in the vicinity of a shear convection reversal and is associated with the upward-directed region 1 field-aligned current. On the other hand, the near-noon cusp auroras (type 1 and 2) are expected to be more directly related to reconnection processes at the magnetopause. They are related to IMF $B_{Y}$-related cusp currents as documented by Erlandson et al. (1988) and Watanabe et al. (1996).

Individual auroral forms are observed to be related to mesoscale currents representing structures embedded within the larger-scale currents in the cusp region (Sandholt et al., 1989b).

During interval I of this case study there is a latitudinally wide band of weak red line emission with almost no green line emission implying a lack of significant acceleration (cf. Fig. 2(a)). Such an auroral form is typical of intervals characterized by slow convection speeds and quiet magnetic conditions, and is often observed at the time of positive IMF $B_{Z}$ component (cf. Sandholt et al., 1996b). This aurora (type 2 cusp aurora) may be the signature of entry of magnetosheath plasma via flux tubes constituting lobe convection cells. 


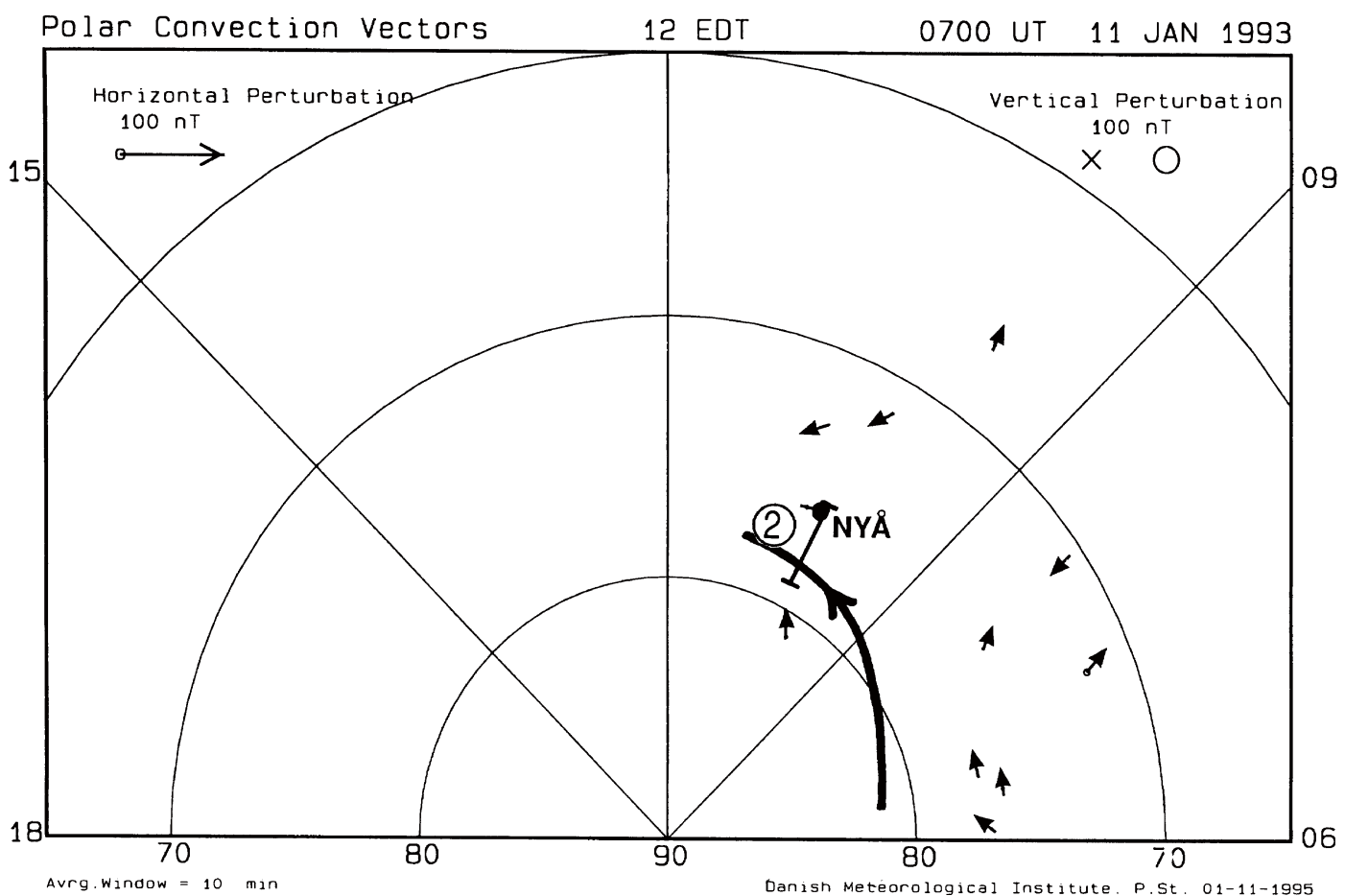

(a)

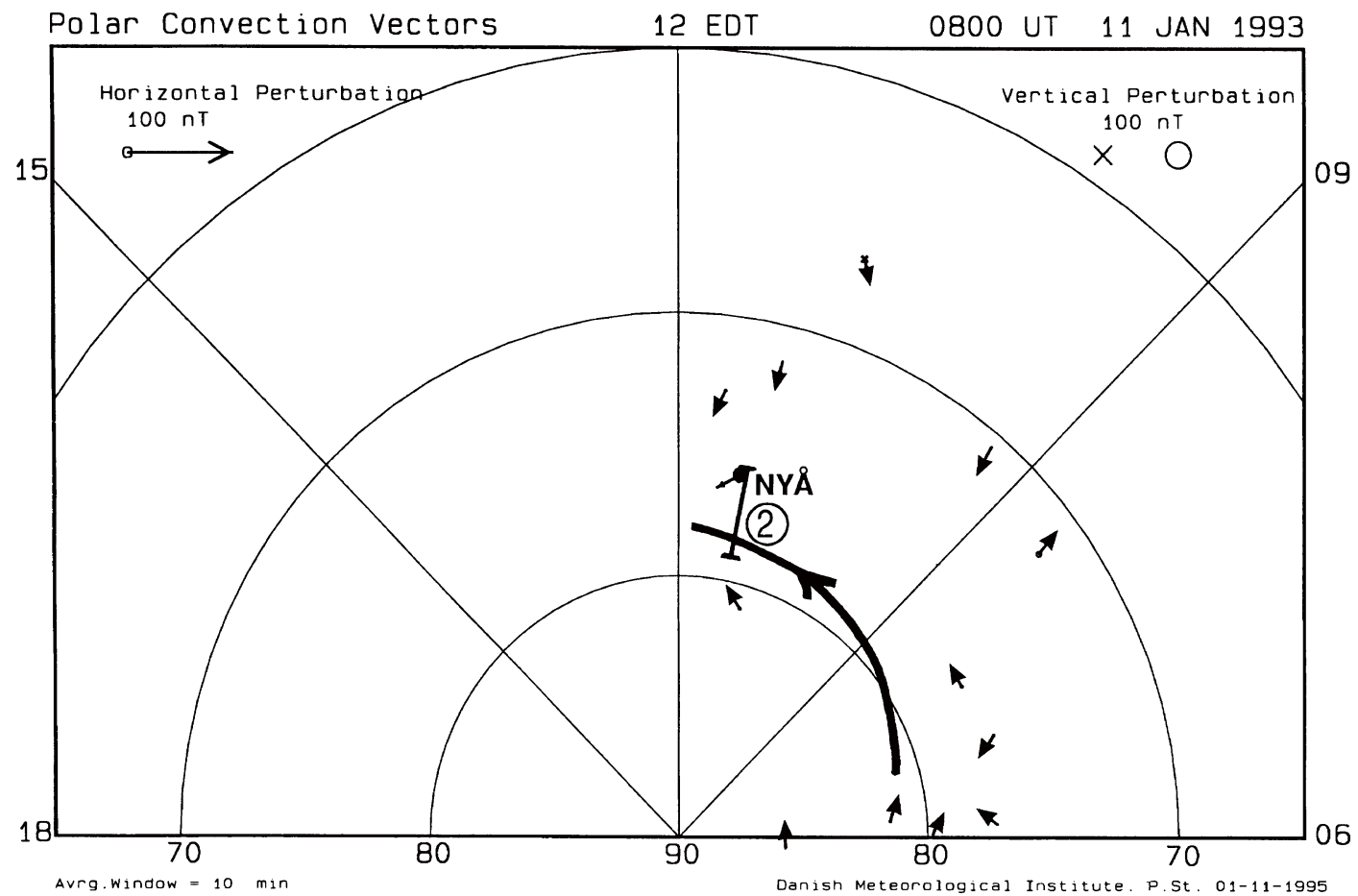

(b)

Fig. 6. Equivalent ionospheric convection derived from ground magnetograms in Greenland and Svalbard for the selected times $0700,0800,0830$ and 0930 UT. The latitudinal location of auroral forms observed from Ny Ålesund (NYA) and Danmarkshavn (DNH) has been marked (cf. text for details). The locations of Ny Ålesund and Danmarkshavn (Fig. 6(d)) are marked by solid dots.

During interval II the type 1 cusp aurora appears at the equatorward edge of the type 2 aurora (cf. Fig. 2(b)). It has a more limited latitudinal extent $(\leq 100 \mathrm{~km})$ and because some $557.7 \mathrm{~nm}$ emission is seen in this region there appears to be some electron acceleration. Both the red and green line intensities are higher than in the type 2 aurora further north. This indicates that a more efficient mechanism of plasma transfer from the solar wind/magnetosheath was involved at 


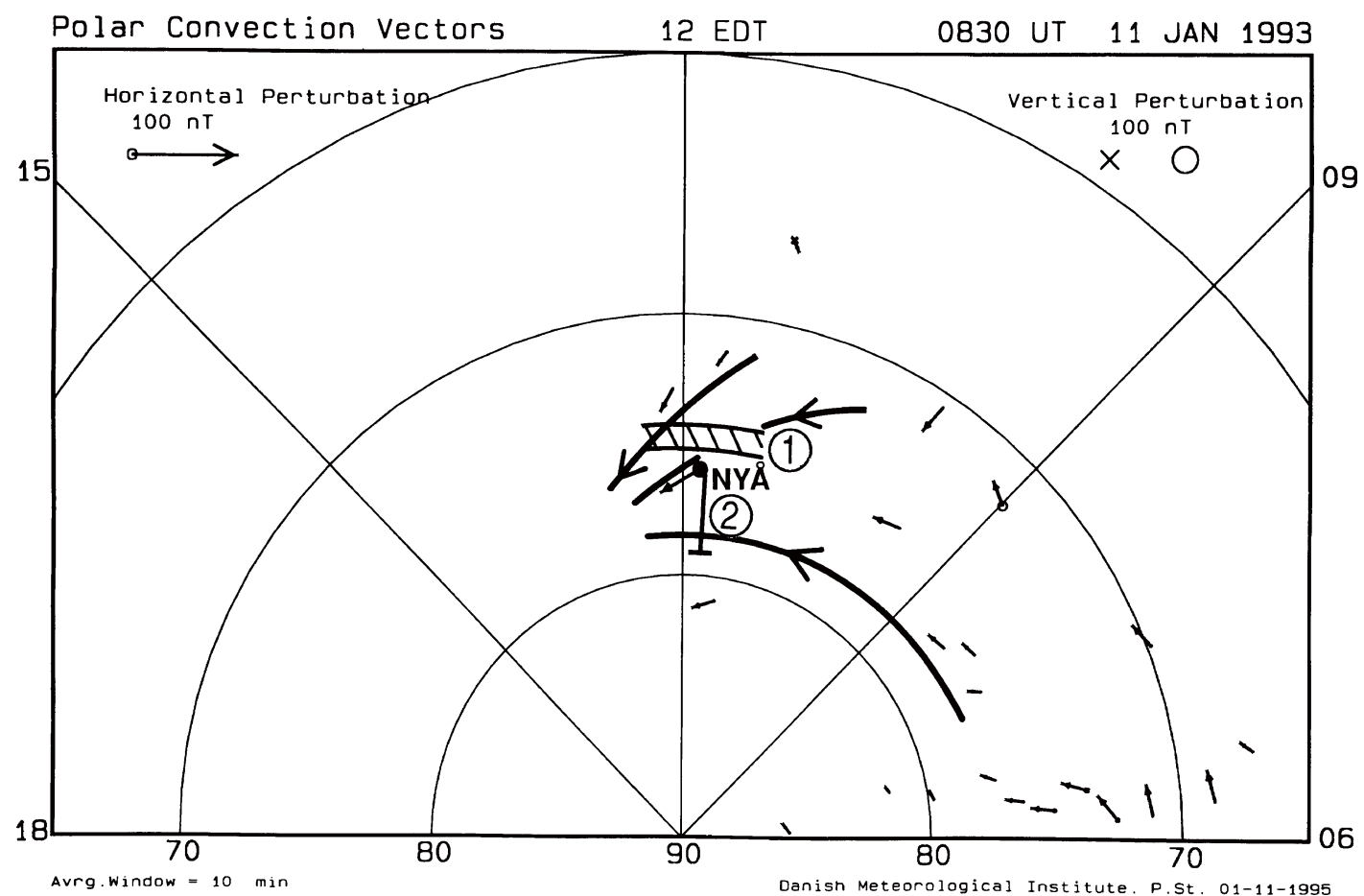

(c)

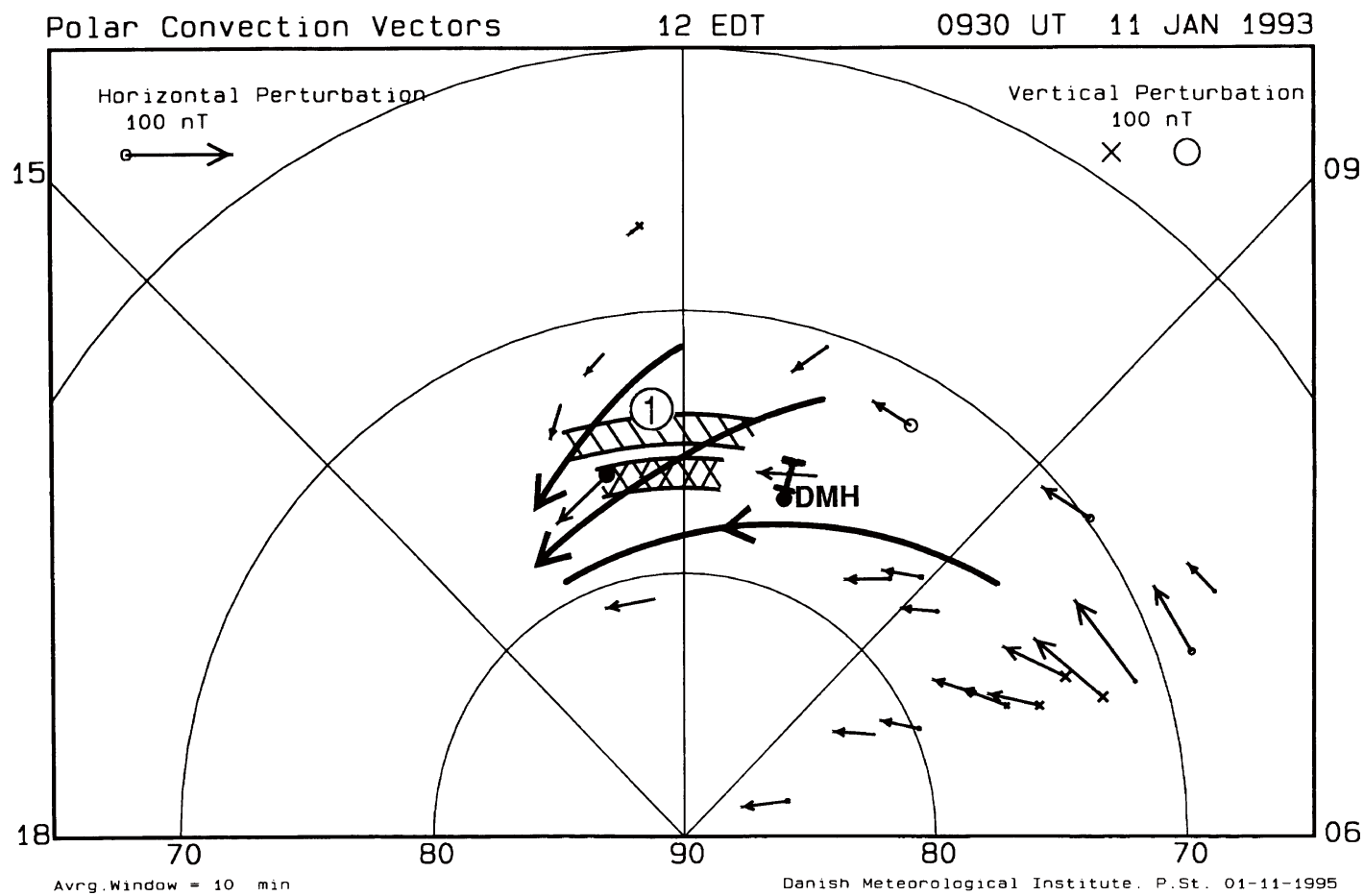

(d)

Fig. 6. (continued)

this time. Part of the difference in emission intensity between the type 1 and type 2 auroras can be due to the different densities of the sheath plasma at low (subsolar region) and high latitudes. It is also noted that the plasma flow works for entry at low latitudes and against entry at high latitudes. Previous studies have documented that the latitudinal location of the type 1 aurora is very sensitive to the IMF $B_{Z}$ component and solar wind dynamic pressure (Sandholt et al., 1994). The plasma source is the LLBL/ cusp. It corresponds to the most efficient plasma transfer in the noon sector. A candidate mechanism is low-latitude reconnection (Onsager et al., 1993). 


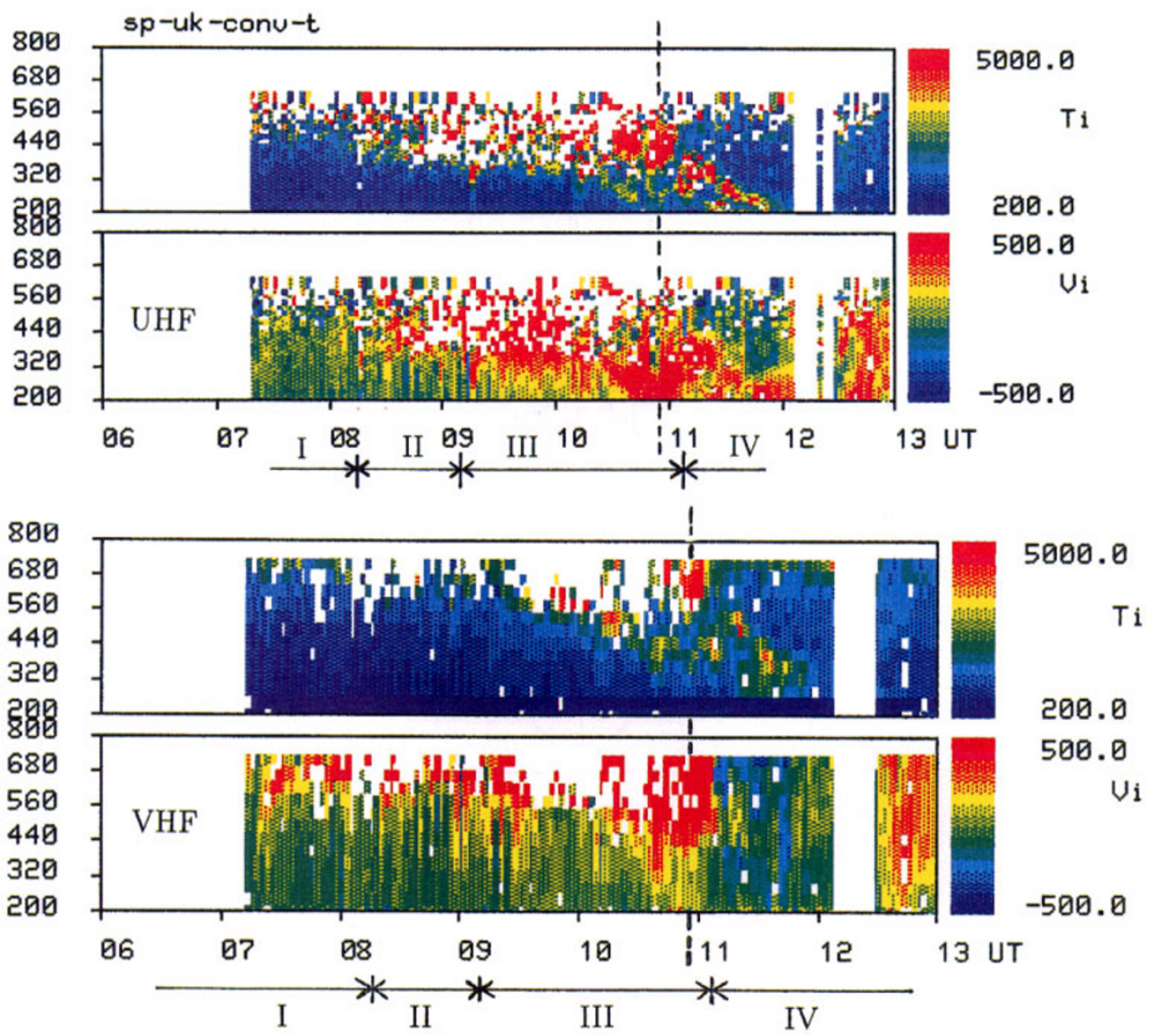

Fig. 7. EISCAT observations of $F$-layer ion temperature and drift for the interval 0710-1205 UT (January 11, 1993). Observations made by the UHF and VHF antennas are shown in the two upper and the two lower panels, respectively. Colour-coded scales are given on the right side. Line-of-sight velocities within $-500 \sim+500 \mathrm{~m} / \mathrm{s}$ are shown. The auroral event onset at 1055 UT is marked by dashed lines. The field-of-views corresponding to the 25 range gates of the two antennas are indicated in Figs. 1, 8 and 10.

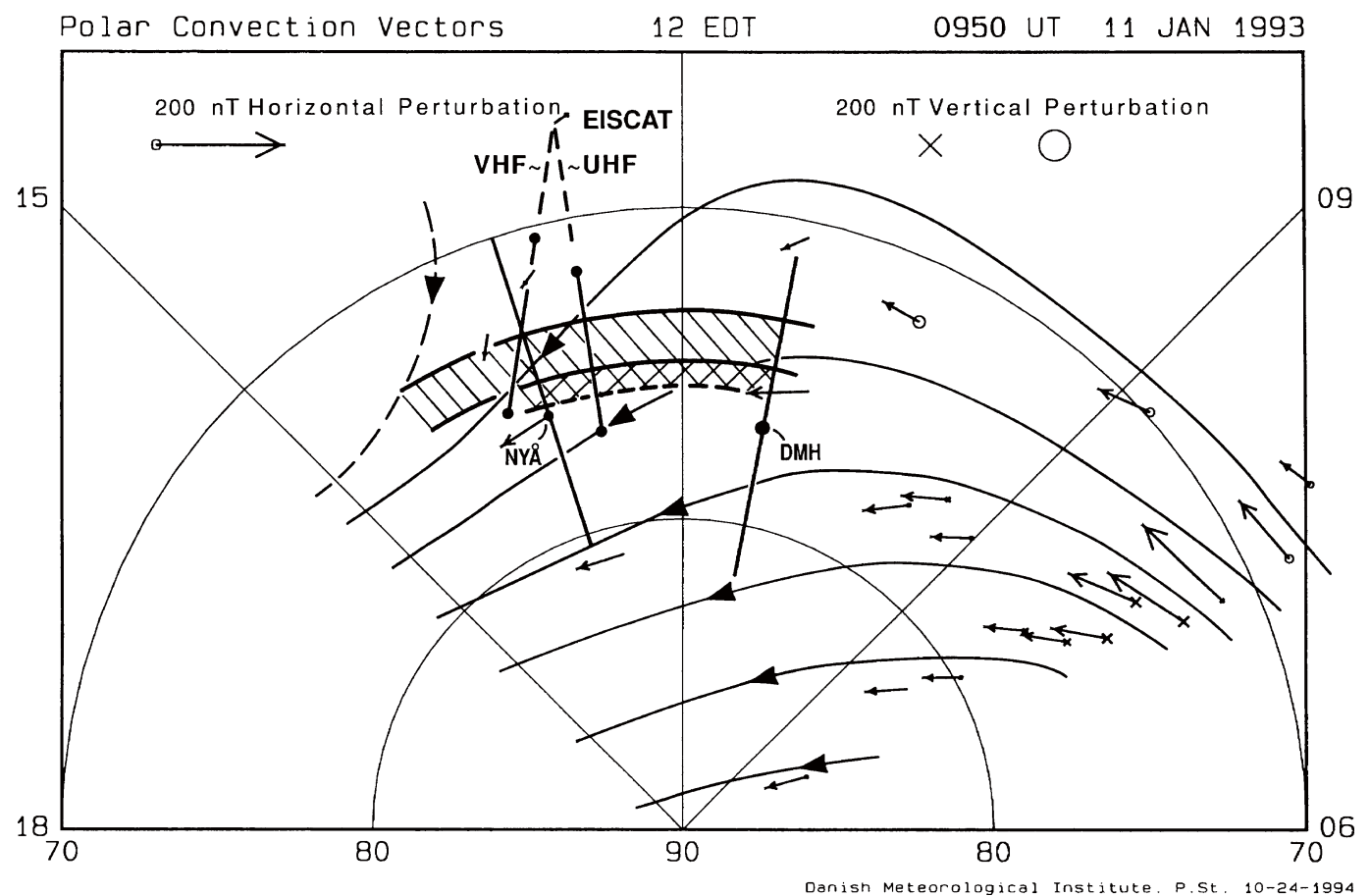

Fig. 8. Map of auroral forms and pattern of ionospheric convection in the sectors of Svalbard and Greenland for 0950 UT, as inferred from EISCAT ion drift and ground magnetometer data. The type 1 cusp aurora and auroral transients at its poleward boundary (cf. Figs. 2(c) and 2(d)) are marked by hatched zone and crosses, respectively. Field-of-views of scanning photometers in Ny Ålesund (NYÅ) and Danmarkshavn (DMH) as well as the EISCAT UHF and VHF antennas are marked by straight lines. 
Experiment : SP-NO-CONV

UHF Azimuth 344 Degrees

Time Interval : 09:30:00 11 January 1993 - 12:00:00 11 January 1993

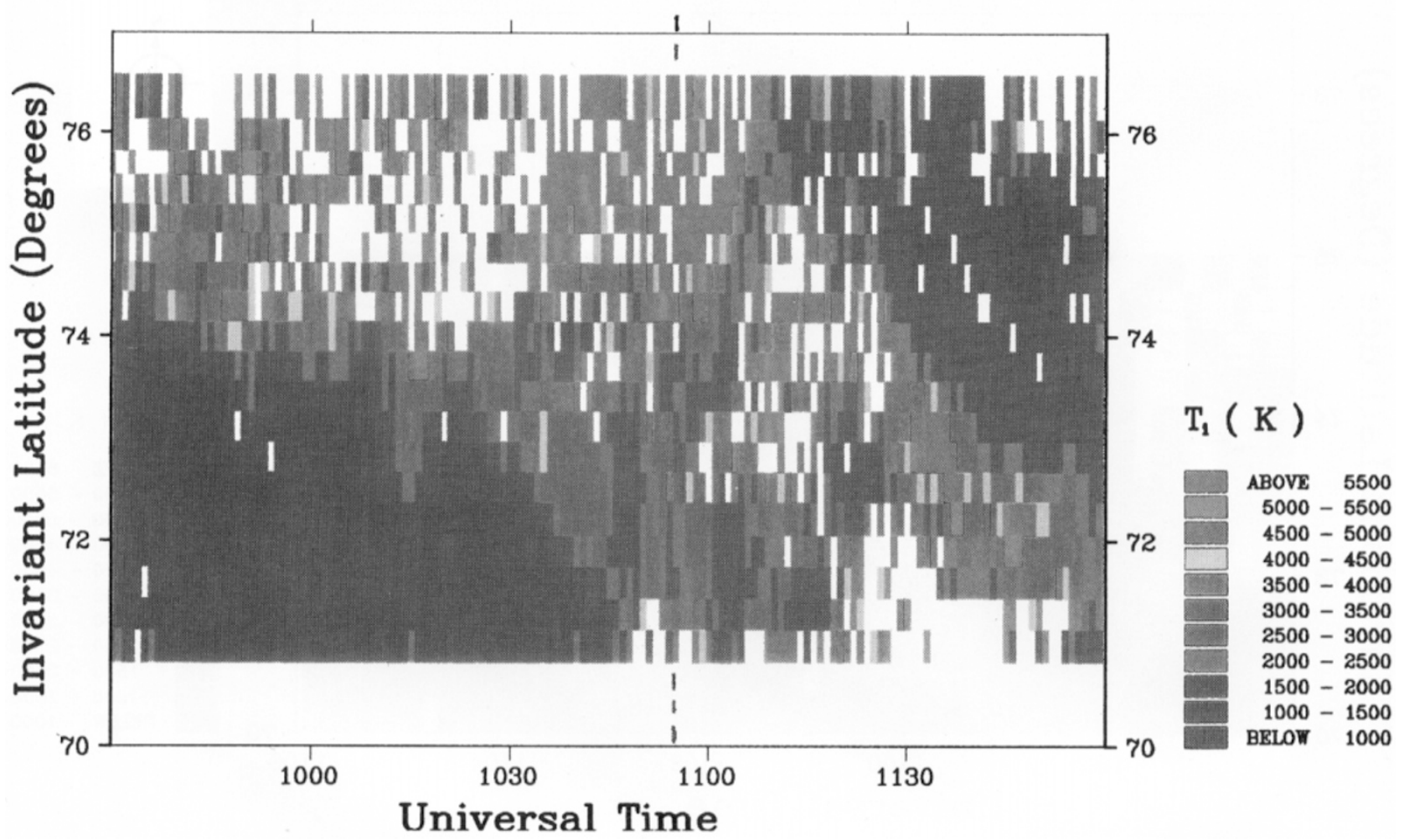

Fig. 9. $F$-layer ion temperature within the latitude range $71-77^{\circ}$ INVL for the interval 0930-1200 UT, as obtained by the EISCAT UHF antenna. The auroral event onset at 1055 UT is marked by dashed vertical line.

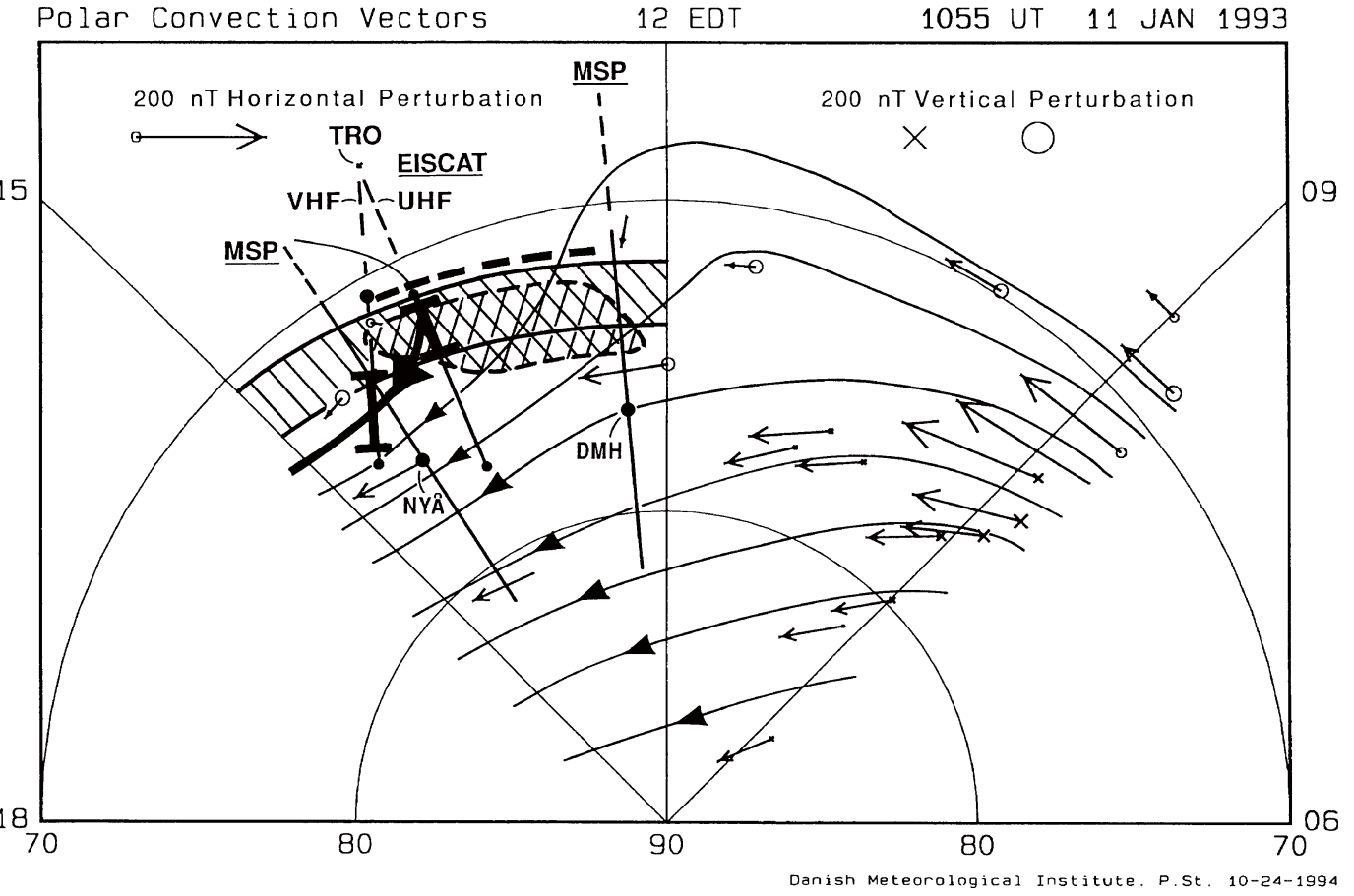

Fig. 10. Map of auroral forms and ionospheric $F$-layer convection in the Svalbard-Greenland sector for 1055-1056 UT, based on optical observations from Ny Ålesund (NYA) and Danmarkshavn (DMH), ion drift obtained by the UHF and VHF antennas of the EISCAT radar as well as ground magnetometer data. The type 1 cusp aurora and the transient auroral form (initial brightening) are marked by single-and cross-hatched areas, respectively (cf. Figs. 2(c) and 2(d)). Regions of strong poleward flow component, measured by EISCAT are marked by bars along the antenna fieldof-views. Rotational flow reversal is marked by thick arrowed curve. Heavy dashed curve marks the estimated location of the open/closed boundary. 
Experiment : SP-NO-CONV

VHF Azimuth 0 Degrees

Time Interval : 10:56:00 11 January 1993 - 11:06:00 11 January 1993

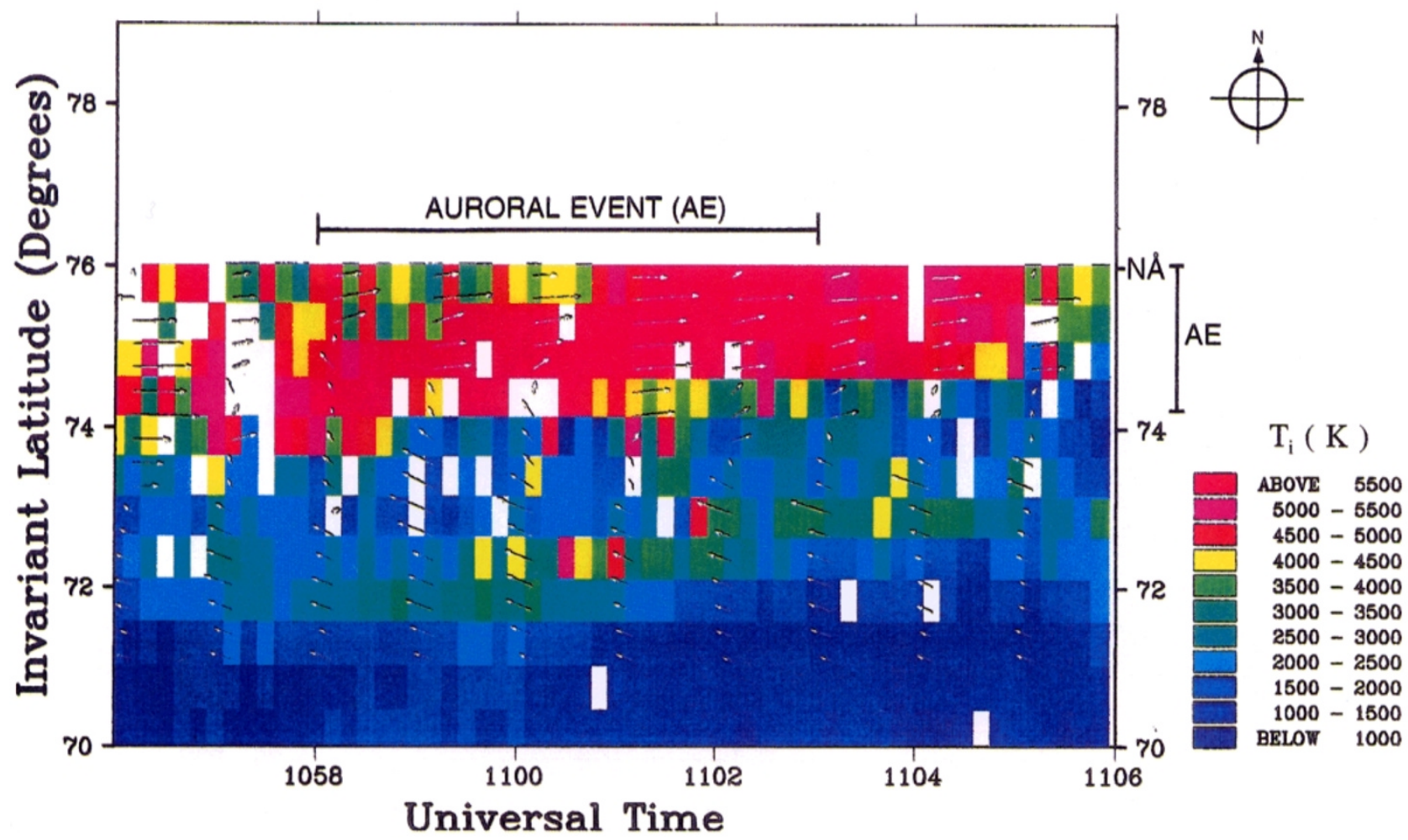

Fig. 11. F-layer ionospheric ion drift (vectors) and ion temperature (colour-coded) in the latitude range $70-76^{\circ}$ INVL for the interval 1056-1106 UT, obtained by the EISCAT UHF and VHF antennas. A transient auroral event $(A E)$ was observed to be colocated with a channel of enhanced eastward flow and elevated temperature immediately poleward of the convection reversal boundary. The vertical bar (AE) marks the latitudinal location of the auroral event.

The coexistence of the two auroral forms (types 1 and 2) at different latitudes during the $\sim 0815-0900$ UT interval (Fig. 2(b)) is consistent with a merging model according to which lobe reconnection and reconnection at sub-cusp latitudes can occur simultaneously (Reiff and Burch, 1985).

The Danmarkshavn photometer data (Fig. 2(d)) reveal an activation of the type 1 cusp aurora in the Greenland sector at $0948 \mathrm{UT}(\sim 11 \mathrm{MLT})$, at the time of the maximum of the associated disturbance in Greenland magnetograms (cf. Fig. 5). A significant intensity decrease occurred at $\sim 1100 \mathrm{UT}$ (12 MLT), at the time when convection slowed and magnetic deflections subsided. Thus, we argue that the type 1 auroral form (narrow, intense red line emission with moderate green line intensity and with sharp equatorward boundary) is the signature of efficient particle entry through the low-latitude boundary layer (LLBL), via the reconnection mechanism which also drives the enhanced convection. This is consistent with in-situ observations of intense fluxes of fieldaligned electrons inside the magnetopause during intervals of subsolar reconnection (cf. Scudder, 1984; Farrugia et al., 1988; Gosling et al., 1990).

The sequence of poleward-moving auroral forms in the cusp region, as seen in Fig. 2(d) (interval III), has been observed in association with the so-called stepped cusp ion dispersion signature, as observed from satellites in polar orbit (Farrugia et al., 1997). This strongly indicates that these auroral forms are related to magnetosheath-origin particles precipitating along open field lines as a result of pulsed magnetopause reconnection.

The different onset times of the type 1 auroral form at $\mathrm{Ny}$ Ålesund ( 0810 UT) and Danmarkshavn (0948 UT) may reflect a spatial structure of the solar wind-magnetosphereionosphere coupling mechanism and the associated pattern of field-aligned currents such that Ny Ålesund rotates into the MLT range where the mechanism is active first; however, the delay is not long enough for this to be the only cause, indicating that the MLT range of the coupling mechanism is expanding and/or migrating to the west and thus to earlier MLT.

The sequence of auroral intensifications recorded by the Danmarkshavn photometer between $~ 0900$ and 0945 UT ( 1000-1045 MLT) was located within a band of magnetic latitudes of about $76-78^{\circ}$, well to the north of the auroral form which appeared after 0948 UT (cf. Fig. 2(d)). The higher-latitude activity may be related to flux tubes convecting in the lobe cell (see Subsection 3.3 below).

3.2 Ion drift and auroral activity in the vicinity of the open/closed boundary in the 11-14 MLT sector

The relationship between the observed auroral forms and plasma convection during the most active periods of this case study, i.e. the intervals 0930-0950 UT and 1050-1105 UT, is summarized in Figs. 8 and 10, respectively. Both 
these intervals are characterized by enhanced convection and corresponding magnetic deflections in the $\sim 0800-1400$ MLT sector. During the first period (0930-0950 UT) a continuous evolution of a convection-bay in the SvalbardGreenland sector is observed (Figs. 4 and 5). A maximum in the magnetic deflection occurred near 0950 UT. The latter interval (1050-1105 UT) includes two discrete events which are manifested in auroral emission, ionospheric ion drift, ion-temperature and ground magnetic deflection.

If the equatorward edge of the type 1 cusp aurora observed in this case is close to (but slightly poleward of) the location of the open/closed field line boundary, as we suggest, plasma flow across the magnetic separatrix, into the polar cap, is observed in the present case (cf. Figs. 8 and 10). This is, by definition, magnetic merging (reconnection). Plasma flow across the separatrix corresponds to an electric field along the magnetopause reconnection X-line (cf. Vasyliunas, 1984). Integrated along the "merging gap" where this electric field exists, the electric field gives the voltage associated with the reconnection process (i.e. the "flux transfer" rate).

The plasma flow patterns in Figs. 8 and 10 are typical examples of rotational convection reversals located within or in the vicinity of the field-of-view of the EISCAT radars, i.e. the reversal spans a latitudinal range of more than 1 degree MLAT and a strong poleward flow component is observed. These are the characteristics of a rotational reversal, as opposed to the shear reversal boundary (cf. Heelis, 1994). Rotational convection reversals are typically observed in the throat region, near magnetic noon (Heelis, 1994). In the present case the convection throat seems to be located in the 13-14 MLT region. It is noted that the convection throat moved westward, towards the prenoon side, associated with a large change of the convection pattern which took place at $\sim 1130$ UT.

Two individual auroral events were observed within the interval 1050-1105 UT. The latter event (1055-1105 UT) appeared at lower latitude than the previous one, i.e. at the equatorward boundary of the pre-existing cusp/cleft aurora, before expanding eastward and poleward (cf. Fig. 3(b)). This auroral event, as well as the previous one, is associated with a poleward-expanding surge of enhanced ionospheric convection and ion-temperature, as can be clearly seen from the EISCAT data presented in Figs. 7, 9 and 11. During 1100-1103 UT this auroral event was observed to be collocated with a channel of enhanced eastward convection and $F$-layer ion temperature, poleward of the convection reversal (Fig. 11). The detailed co-incidence of such auroral events and the local enhancements of $F$-layer ion temperature has also been documented by Lockwood et al. (1995). The magnetic signature of the event on January 11, 1993, at 11 UT (shown in Figs. 3(b), 10 and 11) is observed simultaneously at Ny Ålesund ( 14 MLT) and along the westcoast of Greenland ( 09 MLT). This indicates that the associated convection event is short-lived ( $10 \mathrm{~min})$, but covers a large spatial scale, spanning more than 5 hours of local time, which is equivalent to $\geq 2000 \mathrm{~km}$. Fast ionospheric plasma jets $\left(v>2 \mathrm{~km} \mathrm{~s}^{-1}\right)$ of similar longitudinal extent have been documented by Lockwood et al. (1990b) and Valladares et al. (1994). The optical observations from Ny Ålesund (NYA) and Danmarkshavn (DMH) indicate that the auroral activity is more limited in longitudinal extent. The first event did not propagate as far east as NYA (Fig. 3(a)), but the second intensification did (Fig. 3(b), cf. Fig. 10). Note that without optical observations to the west of DMH the full extent of the auroral event is not known. Information on the auroral activity in the prenoon sector is not available at this time. It is noted that auroral activity in the pre-noon sector was observed from DMH for example around $0950 \mathrm{UT}$, during similar conditions of the largescale polar cap convection as at 1055 UT (see Fig. 8). This means that the actual auroral activity is in general not restricted to the convection throat region.

The present observations, in combination with earlier evidence (Sandholt et al., 1993a, b, 1994; Farrugia et al., 1997), indicate that such events represent an important temporal/spatial structure of merging cell convection and associated cusp precipitation, i.e. representing the evolution of discrete events of open magnetic flux convecting tailward, over the polar magnetosphere, initiated by reconnection rate enhancements at the frontside magnetopause.

The association between a sequence of poleward-moving auroral forms, similar to the events reported here, and the socalled stepped cusp ion dispersion signature (Escoubet et al., 1992; Lockwood and Smith, 1994) has been documented by Farrugia et al. (1998).

\subsection{Theoretical interpretation}

As indicated by the above discussion, an understanding of the observations reported here can be obtained through consideration of the reconnection processes which occur at the magnetopause, how they depend on the direction of the IMF, and how they evolve when the direction of the IMF changes (Cowley and Lockwood, 1992). When the IMF has a steady direction, three basic configurations of ionospheric flow and cusp plasma precipitation may be distinguished, as shown in Fig. 12.

The first configuration occurs when the IMF has a significant northward component. In this case high-latitude reconnection between the IMF and open tail lobe flux takes place, which is assumed here for simplicity to involve one lobe only for a given IMF field line, so that the amount of open flux remains unchanged by this process. The resulting flow and field stresses act on the reconnected open tubes to $<<$ stir $>>$ the open flux into a twin-vortical flow that has IMF $B_{Y}$-dependent asymmetries (Fig. 12(a), shown for IMF $B_{Y}$ negative conditions). The figure also indicates that the $<<$ normal $>>$ twin-vortex flow may often persist at lower latitudes under these circumstances, driven by continued nightside reconnection. The cusp precipitation in this case lies downstream (equatorward of) the ionospheric image of the lobe reconnection site (shown by the heavy dashed lines) which itself lies between the foci of the $<<$ reversed $>>$ flow vortices in the region of open flux. In this case the cusp ion exhibit a falling lower cut-off energy with decreasing latitude in the region between the reconnection site and the open-closed field line boundary $(<<$ reverse $>>$ dispersion indicated by numbered dashed lines which show contours of equal time since reconnection on the downstream field lines; the lower cut-off ion energy decreases as this time increases). This precipitation is inferred to correspond to $<<$ type $2>>$ auroras. Note that the lower-latitude $<<$ normal $>>$ twin- 
(a) IMF $B_{z}>0 ; B_{y}<0$

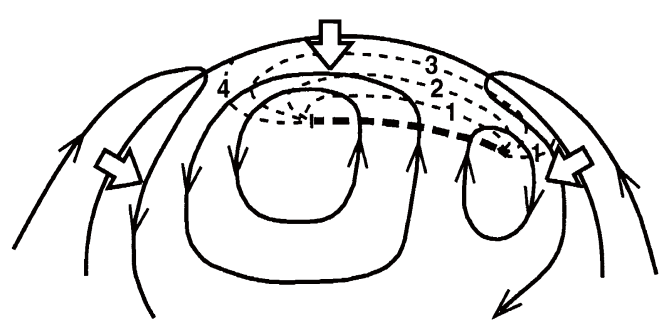

(b) IMF $B_{z} \sim 0 ; B_{y}<0$

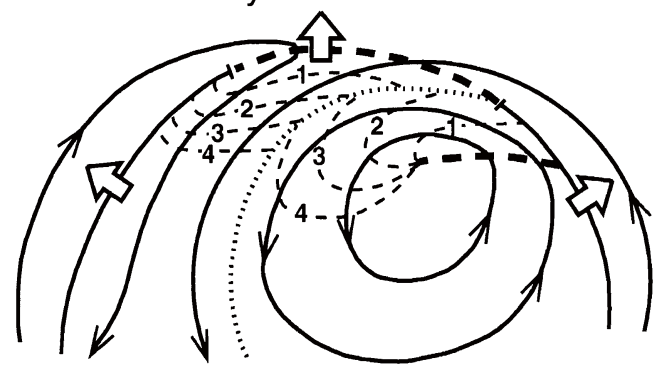

(c) IMF $B_{z}<0 ; B_{y}<0$

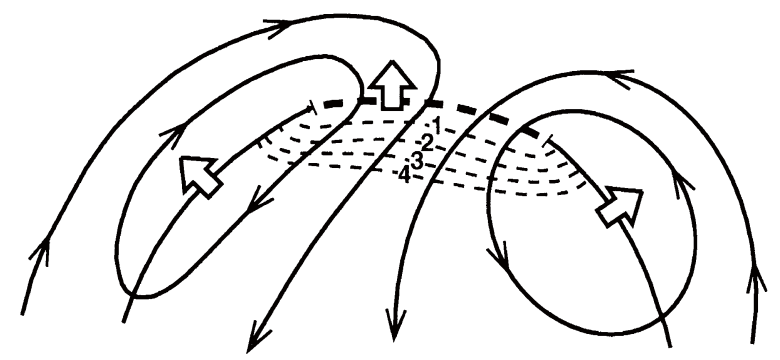

Fig. 12. Sketches of three basic configurations of the northern hemisphere dayside flow and cusp precipitation, corresponding to IMF $B_{Y}$ negative and (a) IMF $B_{Z}$ positive; (b) IMF $B_{Z}$ near zero; and (c) IMF $B_{Z}$ negative. Heavy solid lines represent adiaroic segments of the openclosed field line boundary, arrowed solid lines are streamlines, heavy dashed lines are the ionospheric images of the magnetopause reconnection regions, and numbered dashed lines represent contours of equal time since reconnection downstream from the latter (with the low-energy cut-off in the cusp ions decreasing as this time increases). The large arrows indicate the motions of the open-closed field line boundary.

vortex flow which is driven by tail processes is associated with a contraction of the adiaroic open-closed field line boundary on the dayside (indicated by the large arrows) and that there is no cusp precipitation related to this flow. This configuration (Fig. 12(a)) represents precipitation and convection conditions corresponding to interval I in the present case study.

The second configuration occurs when the IMF has a significant southward component. In this case low-latitude reconnection results in the production of open flux tubes at the dayside magneotpause, which are subsequently swept into the tail by the magnetosheath flow. This process excites a twin-vortex flow in the ionosphere associated with an expanding region of open flux (unless limited by simultaneous reconnection in the tail), with antisunward flow over the polar cap and return sunward flow at lower latitudes (Fig. 12(c)). Dawn-dusk asymmetries are also present, depending on the sense of IMF $B_{Y}$, produced by the magnetic tension forces on the open flux tubes. Conditions in the northern hemisphere for negative IMF $B_{Y}$ are shown in the figure, corresponding to the observations reported here. The cusp (magnetosheath) precipitation under these circumstances is located poleward of the ionospheric image of the reconnection region on the open-closed field line boundary (the $<<$ merging gap $>>$, shown by the heavy dashed line in the figure), with the cusp ions exhibiting a falling lower-cut off energy with increasing latitude ( $<<$ normal $>>$ ion dispersion). This is again indicated in the figure by the numbered dashed lines. We infer that this precipitation region corresponds to the $<<$ type $1>>$ auroras, in which (as noted abovefew-minute transient phenomena, presumably associated with transient changes in the reconnection rate, are commonplace. This configuration (Fig. 12(c)) represents the conditions observed in interval III of this case study.

We note that the falling lower cutoff ion energy with increasing latitude corresponds to the later phase of the poleward-moving auroral forms. This has been documented in ionospheric ionization profiles related to these auroral forms, i.e. increasing $F$-layer peak altitude with increasing latitude (Walker et al., 1998).

The third configuration corresponds to the intermediate case where the dominant IMF component is the $B_{Y}$ component. In this case open flux tube production at lower latitudes can occur simultaneously with lobe reconnection of open flux, leading to the simultaneous excitation of $<<$ normal $>>$ twin-vortex flow at the dayside and IMF $B_{Y^{-}}$ dependent lobe stirring, though in this case only one cell of the latter may typically be present (Fig. 12(b)). In this case both $<<$ normal $>>$ and $<<$ reverse $>>$ dispersion cusp precipitation will simultaneously be present downstream from the respective reconnection regions, and what is observed will depend on local time. For the IMF $B_{Y}$ negative conditions shown in the figure, the $<<$ reverse $>>$ dispersion cusp $(<<$ type $2>>$ aurora) should be dominant in the pre-noon sector, the $<<$ normal $>>$ dispersion cusp post-noon, and there will also be a region of overlap in the noon/pre-noon sector, giving rise to $\mathrm{a}<<\mathrm{V}>>$-shaped ion profile and a broader region of combined auroral emission. For IMF $B_{Y}$ positive these asymmetries would reverse in sense about noon.

This configuration (Fig. 12(b)) represents the conditions in interval II of the present case study. Thus, the observed temporal evolution of the auroral and convection configuration from interval I to interval II and III may be explained by the sequence of states indicated in Fig. 12 and the corresponding changes of the orientation of the interplanetary magnetic field. Auroral observations representing these IMF orientations have been documented by Sandholt et al. (1998).

\section{Summary}

Temporal/spatial structure of auroral activity and associated ionospheric plasma convection in the $1000-1400$ MLT sector has been investigated, based on simultaneous observations on Svalbard and Greenland.

The observations were divided into four intervals according 
to convection level and auroral morphology/activity. The three categories of auroral configurations observed in intervals I, II, and III, involving two types of cusp forms, correspond to different levels of magnetic disturbance and convection intensity. The available information on particle precipitation associated with type 1 cusp auroral forms (Farrugia et al., 1998) was used to identify the approximate location of the open/closed field line boundary.

Interval I (0700-0815 UT; 1000-1115 MLT) is characterised by reverse (sunward) convection in the dayside polar cap, quiet magnetic conditions, and a latitudinally wide $(>200 \mathrm{~km})$ zone of weak $(\sim \leq 1 \mathrm{kR})$ red line emission, extending up to high latitudes $\left(\sim 79^{\circ} \mathrm{MLAT}\right)$. This is the type 2 aurora observed during positive IMF $B_{Z}$ conditions (cf. Sandholt et al., 1996a, b). It is postulated to be the signature of particle entry via magnetic flux tubes constituting the socalled lobe cell convection (cf. Gosling et al., 1991; Reiff and Burch, 1985). Both the particle precipitation and the convection are results of merging between a northwarddirected IMF $\left(B_{Z}>0\right)$ and the geomagnetic field, poleward of the cusp (cf. Kessel et al., 1996).

Interval II ( 0815-0910 UT) shows the appearance of a strong and dynamical $630.0 \mathrm{~nm}$ aurora at lower latitudes $\left(\sim 74-75^{\circ}\right.$ MLAT), which we identify as the type 1 cusp aurora. This auroral form is often observed to be associated with a standard two-cell convection pattern (Sandholt et al., 1994, 1996a). The simultaneous occurrence of the two categories of auroral forms at different latitudes, associated with lobe cell and merging cell convection, respectively is consistent with predictions of the merging model presented by Reiff and Burch (1985). Interval II represents an intermediate state between intervals of dominating high latitude (lobe) reconnection (interval I) and reconnection at lower latitudes, equatorward of the cusp (interval III).

The most prominent auroral activity was observed during interval III, between $\sim 0910$ and 1110 UT, within the local time sector $\sim 1000-1400$ MLT, in association with enhanced convection speeds. Auroral events of $\leq 10$ min duration, with associated convection enhancements and ground magnetic deflections within a wide range of longitudes ( 09-14 MLT) were observed in this interval.

The temporal/spatial evolution of the auroral/convection configuration from interval I to II and III has been explained in terms of a model description of cusp particle precipitation and convection associated with certain variations of the orientation of the interplanetary magnetic field, though no IMF data were available during this period which would allow us to verify this inference.

The auroral events which occurred during interval III appeared at the equatorward boundary of the pre-existing type 1 cusp aurora, before expanding along the polar cap boundary and in the poleward direction. Such auroral events were observed to occur in the vicinity of rotational convection reversals which were directly observed within the fieldof-view of the two EISCAT radars. Thus they were associated with ion drift across the open/closed boundary, within the so-called merging gap. The region of strong poleward ion flow in the vicinity of the poleward-moving auroral forms is marked in Fig. 10. A latitudinal zone of elevated ionospheric ion temperatures was also observed to move poleward with the transient auroral events. Such ion temperature events can be explained as an effect of ion flow bursts (Lockwood et al., 1995).

Ion drift across the magnetic field separatrix is equivalent to the existence of an electric field along a reconnection $\mathrm{X}$ line at the magnetopause (Vasyliunas, 1984). The observed convection enhancements and auroral events are therefore considered to be signatures of a variable magnetopause reconnection rate/reconnection configuration with associated plasma transfer and E-field coupling to the ionosphere. The spatial scale of the ground magnetic signature of these convection events, covering more than $5 \mathrm{hrs}$ in local time, indicate that this is a large-scale coupling process. The idea of large-scale modulations of the magnetopause reconnection-rate/configuration has been discussed in several theoretical and experimental studies (e.g. Southwood $e t$ al., 1988; Scholer, 1988; Lockwood et al., 1990a, b; Pinnock et al., 1993; Moen et al., 1995).

The present study adds new information on the temporal/ spatial evolution of the auroral precipitation and its detailed relationships with ionospheric convection in the dayside polar ionosphere (cf. Figs. 6, 8 and 10), as inferred from ground magnetic perturbations in the sectors of Svalbard and Greenland as well as the EISCAT radar. When discussing the source(s) of the indicated modulations of the solar wind-magnetosphere coupling rate, e.g. the question of spontaneous versus triggered events, a good monitoring of external conditions, such as the IMF and solar wind plasma parameters, is required. Such information is not available for the present case. The association between the different auroral and convection configurations seen in intervals I, II and III and the IMF orientation has been documented in a series of recent publications (e.g. Farrugia et al., 1995; Sandholt et al., 1996a, b, 1998).

Acknowledgments. We thank Torleif Sten and Bjørn Lybekk, University of Oslo, for preparing the optical instruments operated in Svalbard and Greenland. Thanks are also due to Ole Rasmussen, DMI, Copenhagen, for the operation of the Danish magnetic observations in Greenland, to Børre Holmeslet, The Auroral Observatory, Troms $\varnothing$, for supplying the data from the NorthNorwegian magnetometers, and to C. R. Clauer for the supply of data from the MAGIC stations in Greenland (ice-cap stations). Support for the MAGIC data acquisition has been provided by NSF grant ATM-9106958. The optical observation program in Svalbard is supported by the Norwegian Polar Research Institute and the Norwegian Research Council (Norges Forskningsråd).

\section{References}

Cowley, S. W. H. and M. Lockwood, Excitation and decay of solar winddriven flows in the magnetopshere-ionosphere system, Ann. Geophysicae, 10, 103, 1992.

Erlandson, R. E., L. J. Zanetti, T. A. Potemra, P. F. Bythrow, and R. Lundin, IMF $B_{Y}$ dependence of region 1 Birkeland currents near noon, J. Geophys. Res., 93, 9804, 1988.

Escoubet, C. P., M. F. Smith, S. F. Fung, P. C. Anderson, R. H. Hoffman, E. M. Basinska, and J. M. Bosqued, Staircase ion signature in the polar cusp: A case study, Geophys. Res. Lett., 19, 1735, 1992.

Farrugia, C. J., R. P. Rijnbeek, M. A. Saunders, D. J. Southwood, D. J. Rodgers, M. F. Smith, C. P. Chaloner, D. S. Hall, P. J. Christiansen, and L. J. C. Woolliscroft, A multi-instrument study of flux transfer event structure, J. Geophys. Res., 93, 14465, 1988.

Farrugia, C. J., P. E. Sandholt, S. W. H. Cowley, D. J. Southwood, A. 
Egeland, P. Stauning, R. P. Lepping, A. J. Lazarus, T. Hansen, and E. Friis-Christensen, Reconnection-associated auroral activity stimulated by two types of upstream dynamic pressure variations: Interplanetary magnetic field $B_{Z} \sim \mathrm{O}, B_{Y}<<$ O case, J. Geophys. Res., 100, 21753, 1995

Farrugia, C. J., P.E. Sandholt, W. F. Denig, and R. B. Torbet, Observations of a correspondence between poleward-moving auroral forms and stepped cusp ion precipitation, J. Geophys. Res., 103, 9309-9315, 1998.

Gosling, J. T., M. F. Thomsen, S. J. Bame, T. G. Onsager, and C. T. Russell, The electron edge of the low-latitude boundary layer during accelerated flow events, Geophys. Res. Lett., 17, 1833, 1990.

Gosling, J. T., M. F. Thomsen, S. J. Bame, R. C. Elphic, and C. T. Russell, Observations of reconnection of interplanetary and lobe magnetic field lines at the high-latitude magnetopause, J. Geophys. Res., 96, 14097 1991

Heelis, R. A., Thermal ion drifts in the dayside high-latitude ionosphere, in Physical Signatures of Magnetospheric Boundary Layer Processes, NATO ASI Ser. C/Vol. 425, edited by J. A. Holtet and A. Egeland, pp. 43, Kluwer Academic Publ. Dordrecht, The Netherlands, 1994

Heppner, J. P. and N. C. Maynard, Empirical high-latitude electric field models, J. Geophys. Res., 92, 4467, 1987.

Kessel, R. L., S. H. Chen, J. L. Green, S. F. Fung, S. A. Boardsen, L. C. Tan, T. E. Eastman, J. D. Craven, and L. A. Frank, Evidence of highlatitude reconnection during northward IMF: Hawkeye observations, Geophys. Res. Lett., 23, 583, 1996.

Lockwood, M. and M. F. Smith, Low and middle altitude cusp particle signatures for general magnetopause reconnection rate variations; 1. Theory, J. Geophys. Res., 99, 8531, 1994.

Lockwood, M., S. W. H. Cowley, and P. E. Sandholt, Transient reconnection: search for ionospheric signatures, EOS, Trans. Am. Geophys. Union, 71, 709, 1990a.

Lockwood, M., S. W. H. Cowley, P. E. Sandholt, and R. P. Lepping, The ionospheric signature of flux transfer events and solar wind dynamic pressures changes, J. Geophys. Res., 95, 17113, 1990b.

Lockwood, M., J. Moen, S. W. H. Cowley, A. D. Farmer, V. P. Løvhaug, and V. N. Davda, Variability of dayside convection and motions of the cusp/cleft aurora, Geophys. Res. Lett., 20, 1011, 1993.

Lockwood, M., S. W. H. Cowley, P. E. Sandholt, and U. P. Løvhaug, Causes of plasma flow bursts and dayside auroral transients: An evaluation of two models invoking reconnection pulses and changes in the $y$-component of the magnetosheath field, J. Geophys. Res., 100, 7613, 1995.

Lundin, R., J. Woch, and M. Yamauchi, The present understanding of the cusp, in Cluster-Dayside Polar Cusp, Eur. Space Agency Spec. Publ., SP-330, pp. 83, 1991

Moen, J., P. E. Sandholt, M. Lockwood, W. F. Denig, U. P. Løvhaug, B. Lybekk, A. Egeland, D. Opsvik, and E. Friis-Christensen, Events of enhanced convection and related dayside auroral activity, J. Geophys. Res., 100, 23,917-23,934, 1995.

Newell, P. T. and C.-I. Meng, The cusp and cleft/LLBL: Low altitude identification and statistical local time variation, J. Geophys. Res., 93, 14549, 1988.

Newell, P. T. and C.-I. Meng, Mapping the dayside ionosphere to the magnetosphere according to particle precipitation characteristics, Geophys. Res. Lett., 19, 609, 1992.

Øieroset, M., P. E. Sandholt, H. Lühr, W. F. Denig, and T. Moretto, Auroral and geomagnetic events at cusp/mantle latitudes in the prenoon sector during positive IMF $B_{Y}$ conditions: Signatures of pulsed magnetopause reconnection, J. Geophys. Res., 102, 7191, 1997a.

Øieroset, M., P. E. Sandholt, W. F. Dening, and S. W. H. Cowley, Northward interplantetary magnetic field cusp aurora and high-latitude magnetopause reconnection, J. Geophys. Res., 102, 11349, 1997b.

Onsager, T. G., C. A. Kletzing, J. B. Austin, and H. MacKierman, Model of magnetosheath plasma in the magnetosphere: Cusp and mantle particles at low altitudes, Geophys. Res. Lett, 20, 479, 1993.

Pinnock, M., A. S. Rodger, J. R. Dudeney, K. B. Baker, P. T. Newell, R. A. Greenwald, and M. E. Greenspean, Observations of an enhanced convection channel in the cusp ionosphere, J. Geophys. Res., 98, 3767,
1993.

Reiff, P. H. and J. L. Burch, IMF $B_{Y}$-dependent plasma flow and Birkeland currents in the dayside magnetosphere. 2. A global model for northward and southward IMF, J. Geophys. Res., 90, 1595, 1985.

Rich, F. J. and M. Hairston, Large-scale convection patterns observed by DMSP, J. Geophys. Res., 99, 3827, 1994.

Russell, C. T. and R. C. Elphic, ISEE observations of flux transfer events at the dayside magnetopause, Geophys. Res. Lett., 6, 33, 1979.

Sandholt, P. E. and P. T. Newell, Ground and satellite observations of an auroral event at the cusp/cleft equatorward boundary, J. Geophys. Res., 97, 8685, 1992.

Sandholt, P. E., B. Lybekk, A. Egeland, R. Nakamura, and T. Oguti, Midday auroral breakup, J. Geomag. Geoelectr., 41, 371, 1989a.

Sandholt, P. E., B. Jacobsen, B. Lybekk, A. Egeland, P. F. Bythrow, and D. A. Hardy, Electrodynamics of the polar cusp ionosphere: A case study, J. Geophys. Res., 94, 1989b.

Sandholt, P. E., J. Moen, A. Rudland, D. Opsvik, W. F. Denig, and T. Hansen, Auroral event sequence at the dayside polar cap boundary for positive and negative IMF $B_{Y}, J$. Geophys. Res., 98, 7737, 1993a.

Sandholt, P. E., J. Moen, D. Opsvik, W. F. Denig, and W. J. Burke, Auroral event sequence at the dayside polar cap boundary: signature of time-varying solar wind-magnetosphere-ionosphere coupling, $A d v$. Space Res., 13(4), 7, 1993 b.

Sandholt, P. E., C. J. Farrugia, L. F. Burlaga, J. A. Holtet, J. Moen, B. Lybekk, B. Jacobsen, D. Opsvik, A. Egeland, R. Lepping, A. J. Lazarus, T. Hansen, A. Brekke, and E. Friis-Christensen, Cusp/cleft auroral activity in relation to solar wind dynamic pressure, IMF $B_{Z}$ and $B_{Y}$, J. Geophys. Res., 99, 17323, 1994.

Sandholt, P. E., C. J. Farrugia, P. Stauning, S. W. H. Cowley, and T. Hansen, Cusp/cleft auroral forms and activities in relation to ionospheric convection: responses to specific changes in solar wind plasma and interplanetary magnetic field conditions, J. Geophys. Res., 101, 5003, 1996a.

Sandholt, P. E., C. J. Farrugia, M. Øieroset, P. Stauning, and S. W. H. Cowley, Auroral signature of lobe reconnection, Geophys. Res. Lett., 23, 1725, 1996b

Sandholt, P. E., C. J. Farrugia, J. Moen, and S. W. H. Cowley, Dayside auroral configurations: Responses to southward and northward rotations of the interplanetary magnetic field, J. Geophys. Res., 1998 (in press).

Scholer, M., Magnetic flux transfer at the magnetopause based on single X-line bursty reconnection, Geophys. Res. Lett, 15, 291, 1988.

Scudder, J. D., K. W. Ogilvie, and C. T. Russell, The relation of flux transfer events to magnetic reconnection, in Magnetic Reconnection in Space and Laboratory Plasmas, edited by E. W. Hones, Jr., pp. 153, Geophysical Monograph 30, AGU, Washington, D.C., 1984.

Southwood, D. J., C. J. Farrugia, and M. A. Saunders, What are flux transfer events?, Planet. Space Sci., 36, 503, 1988.

Stauning, P., E. Friis-Christensen, O. Rasmussen, and S. Vennerstrøm, Progressing polar convection disturbances: signature of an open magnetosphere, J. Geophys. Res., 99, 11303, 1994.

Valladares, C. E., S. Basu, J. Buchan, and E. Friis-Christensen, Experimental evidence for the formation and entry of patches into the polar cap, Radio Sci., 29, 167, 1994.

Vasyliunas, V. M., Steady state aspects of magnetic field line merging, in Magnetic Reconnection in Space and Laboratory Plasmas, edited by E. W. Hones, Jr., pp. 25, Geophysical Monograph 30, AGU, Washington D.C., 1984.

Walker, I. K., J. Moen, C. N. Mitchell, L. Kersley, and P. E. Sandholt, Ionospheric effects of magnetopause reconnection observed using ionospheric tomography, Geophys. Res. Lett., 25, 293, 1998.

Watanabe, M., T. Iijima, and F. Rich, Synthesis model of dayside fieldaligned currents for strong interplanetary magnetic field $B_{Y}, J$. Geophys. Res., 101, 13303, 1996.

P.E.Sandholt(e-mail: p.e.sandholt@fys.uio.no), J. Moen, P. Stauning, J. A. Holtet, S. W. H. Cowley, M. Lockwood, U. P. Løvhaug, T. Hansen, and A. Egeland 